Document de Recherche du Laboratoire d'Économie d'Orléans

DR LEO 2016-05

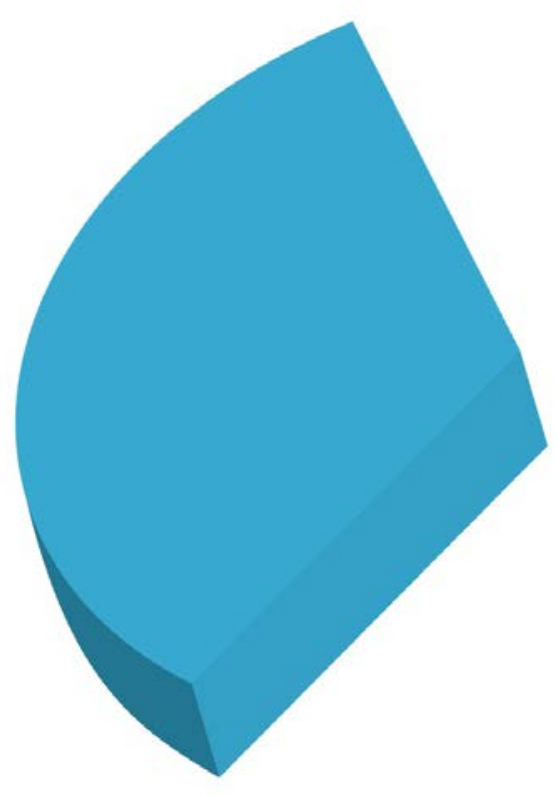

Interaction Matrix Selection in Spatial

Econometrics with an Application to Growth Theory

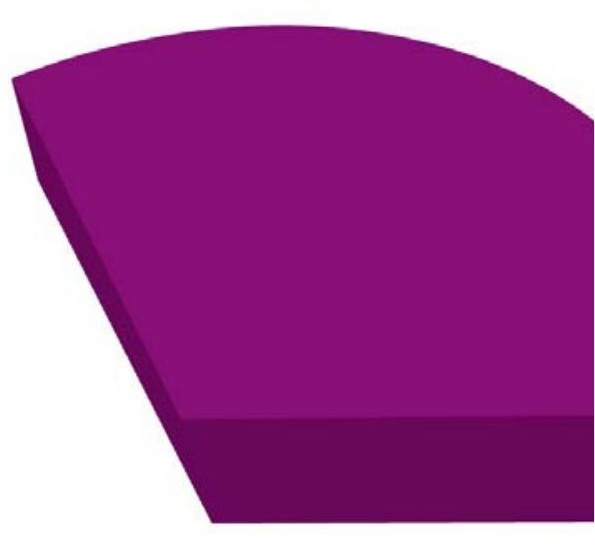

\author{
Nicolas DEBARSY \\ Cem ERTUR
}

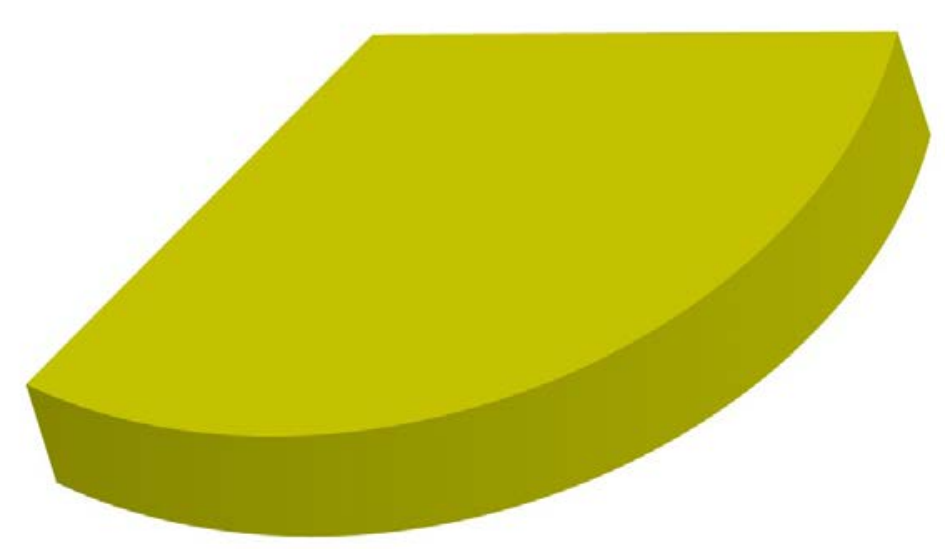




\title{
Interaction matrix selection in spatial econometrics with an application to growth theory
}

\author{
Nicolas Debarsy ${ }^{* \dagger} \quad$ Cem Ertur ${ }^{\ddagger}$
}

\begin{abstract}
The interaction matrix, or spatial weight matrix, is the fundamental tool to model crosssectional interdependence between observations in spatial econometric models. However, it is most of the time not derived from theory, as it should be ideally, but chosen on an ad hoc basis. In this paper, we propose a modified version of the $J$ test to formally select the interaction matrix. Our methodology is based on the application of the robust against unknown heteroskedasticity GMM estimation method, developed by Lin \& Lee (2010). We then implement the testing procedure developed by Hagemann (2012) to overcome the decision problem inherent to non-nested models tests.

An application of the testing procedure is presented for the Schumpeterian growth model with worldwide interactions (Ertur \& Koch 2011) using three different types of interaction matrices: genetic distance, linguistic distance and bilateral trade flows. We find that the interaction matrix based on trade flows is the most adequate. Finally, we propose a network based innovative representation of spatial econometric results.
\end{abstract}

Keywords: Bootstrap; GMM; Interaction matrix; $J$ tests ; Non-nested models; Heteroskedasticity; Spatial autoregressive model

JEL classification: C21- C12 - C52 - O4

\footnotetext{
${ }^{*}$ Corresponding author

${ }^{\dagger}$ CNRS, LEO UMR 7322, Rue de Blois, BP26739, 45067 Orléans, France, Email: nicolas.debarsy@cnrs.fr

†LEO UMR 7322, 45067, Orléans, France, Email: cem.ertur@univ-orleans.fr
} 


\section{Introduction}

The interaction matrix, or spatial weight matrix, is the fundamental tool needed to model crosssectional interdependence between observations in spatial econometric models. It allows to specify the structure of interaction or connectivity within a system through a spatial econometric model and is presumed to be known and exogenous (Anselin \& Bera 1998). However, it is most of the time not derived from theory, as it should be ideally, but chosen on an ad hoc basis. In practice, an applied researcher has to choose a priori the interaction matrix, most of the time without any theoretical guidance. As a result, in empirical studies, interaction matrices are generally based on geographical distance, whose exogeneity is widely admitted. Nevertheless, other concepts of similarity or proximity can be useful to explain interactions. Indeed, by analogy to Akerlof (1997), countries or regions can be seen as localized in some general socio-economic, institutional or political space defined by a set of factors. Implementation of spatial econometric models thus requires the proper definition of the similarity or proximity measure to be used for building the interaction matrix.

Moreover, the consequences of a misspecification of the interaction matrix can be severe. For example, Lee (2008) shows that the misspecification of the interaction matrix can cause a significant bias in the estimates of the spatial autoregressive parameter in a SAR model. If the interaction matrix is under-specified, then both the two stage least squares (2SLS) and maximum likelihood (ML) estimator of the spatial autoregressive parameter are biased downward. Inversely, if the interaction matrix is over-specified, the spatial autoregressive parameter is overestimated. Furthermore, the under-specification of the interaction matrix is more problematic than its over-specification in terms of both bias and RMSE.

A special attention should therefore be given to the choice of the interaction matrix since it is given its specific characteristics that spatial econometric models are estimated and cross-sectional interdependence as well as spillovers are evaluated. One of the key points in the specification of spatial econometric models is then the choice, given a criterion, of the most relevant interaction 
matrix in a subset of all possible matrices.

As different types of interaction structures can be specified to study the same phenomenon, it can prove to be difficult to identify the most appropriate interaction matrix. The literature on the tests of non-nested models has nevertheless made possible the handling of such situations. The literature devoted to the tests of non-nested assumptions finds its origins in many papers including those of Cox (1961, 1962), Atkinson (1970), Davidson \& MacKinnon (1981), Pesaran (1974), Pesaran \& Deaton (1978), MacKinnon et al. (1983), Godfrey (1983) and Pesaran \& Weeks (2001). The tests of non-nested models are classified in two broad categories. The first one is the test of Cox $(1961,1962)$, adapted to linear regression models by Pesaran (1974) and to nonlinear regression models by Pesaran \& Deaton (1978). The second category is due to Davidson \& MacKinnon (1981). These authors develop several procedures, closely related to each others, which may be used to test against several alternative models simultaneously.

In the spatial econometrics literature, one can find a first contribution in Anselin (1988). More recently, Kelejian (2008) extended the $J$ test of Davidson \& MacKinnon (1981) to a spatial context. ${ }^{1}$ The principle of the $J$ test is to estimate a model which contains the null model and the predictive power of alternative models. Then the significance of additional terms is tested. Since this test does not use available information in an efficient way, Kelejian \& Piras (2011) and Burridge (2012) suggest different improvements. Kelejian \& Piras (2011) modify the way available information is used in determining the predictions and consequently improve the power of the $J$ test. Burridge (2012) advocates the use of parameter estimates obtained from maximum likelihood estimation. Finally in an alternative approach, Jin \& Lee (2013) extend the Cox test (Cox 1961, 1962) to a spatial framework. Moreover, in the closely related econometric network literature, an extension of the Kelejian's (2008) $J$ test is proposed by Liu et al. (2014) to differentiate between the localaggregate and the local-average endogenous peer effects in an econometric network model with network fixed effects.

We propose in this paper a modified version of the $J$ test based on the Robust to unknown

\footnotetext{
${ }^{1}$ Not to be confused with the Hansen-Sargan $J$ test for over-identification in GMM estimation.
} 
heteroskedasticity Generalized Method of Moments (RGMM) estimation method elaborated by Lin \& Lee (2010). However it is well known in the literature that all the non-nested hypotheses tests suffer from a decision problem: in some circumstances, they may not help discriminating between the null and alternative models. To overcome this decision problem, Hagemann (2012) recently suggests a simple test for non-nested models, namely the $M J$ test, that we present here in the framework of spatial econometric models.

We finally apply the preceding non-nested hypothesis tests to the generalized Schumpeterian growth model proposed by Ertur \& Koch (2011). These authors propose a theoretical and methodological framework taking into account technological interactions between countries to explain the growth process in a Schumpeterian perspective. Worldwide interdependence, implied by international R\&D spillovers, are therefore structurally introduced in a growth model with technological interactions, which yields a spatial econometric reduced form. This model includes both factor accumulation and innovation caused by R\&D investments as determinants of the growth process, with technological diffusion occurring between interacting pairs of countries, human capital, reflecting the capacity for absorption of technology and physical capital playing the usual part.

In this paper, we consider three different interaction schemes to model the links between countries. The first one is based on genealogical or genetic distance, also called coancestory coefficient Reynolds et al. (1983). This concept of distance, defined by Spolaore \& Wacziarg (2009, 2013), based on Cavalli-Sforza et al. (1994), corresponds to the time elapsed since two populations shared a common ancestor. ${ }^{2}$

In this setting, genealogical distance is considered as a proxy for cultural, institutional and linguistic similarities. The results of Spolaore \& Wacziarg (2009) suggest that this general measure of genealogical relatedness between populations can explain cross-country income differences. Their interpretation is that genealogical distance captures the obstacles to the diffusion of development. The second interaction matrix we consider is based on linguistic proximity following Melitz \&

\footnotetext{
${ }^{2}$ For other empirical works taking into account the ancestral composition of current populations see also Putterman \& Weil (2010); Comin et al. (2010); Ashraf \& Galor (2013).
} 
Toubal (2014). Melitz \& Toubal (2014) summarize the evidence about the linguistic influences in an index, named Common Language Index (CL), resting strictly on exogenous linguistic factors. This summary index (CL) is constructed from different proxies: Common Official Language (COL), Common Native Language (CNL) and Language Proximity (LP). The third interaction matrix used is based on trade flows. Indeed, trade flows may proxy multi-country technological interactions.

The use of the $M J$ test provides considerable help in the selection of the interaction matrix. Indeed, in the context of this application, we show that the trade flows based interaction matrix is the most appropriate pattern to model interactions between countries, among the three types of interaction patterns we consider. Furthermore, we propose a network based innovative representation of spatial econometric results. The obtained graphs significantly contribute to the interpretation of the estimated model.

The remainder of the paper is organized as follows: in section 2, we present the RGMM estimation approach robust to unknown heteroskedasticity elaborated by Lin \& Lee (2010). Section 3 is devoted to model interpretation. Our modified version of the $J$ test test based on RGMM estimation as well as the predictor selection are then presented in section 4 . The $M J$ test framework recently developed by Hagemann (2012) is then applied to our specific context of interaction

matrix selection in section 5. Section 6 presents the application to the generalized Schumpeterian growth model while section 7 concludes.

\section{GMM robust to heteroskedasticity}

The model considered in this paper is the heteroskedastic SAR specification

$$
Y_{n}=X_{n} \beta_{0}+\lambda_{0} W_{n} Y_{n}+\varepsilon_{n}
$$

where $X_{n}$ is a $n \times k$ matrix of exogenous and non-stochastic explanatory variables, $W_{n}$ is a nonstochastic interaction matrix whose diagonal elements are zero, $\lambda_{0}$ is the true parameter measuring 
interactions' intensity while $\beta_{0}$ is the true $k \times 1$ vector of unknown parameters associated to the explanatory variables. Finally, $\varepsilon_{n}$ is the vector of independent error terms with $\varepsilon_{i n}$ characterized by a zero mean and a variance $\sigma_{i n}^{2}, i=1, \cdots, n$. We also note $\theta_{0}=\left[\lambda_{0}, \beta_{0}^{\prime}\right]^{\prime}$ and $\theta=\left[\lambda, \beta^{\prime}\right]^{\prime}$ for any value of $\lambda$ and $\beta .{ }^{3}$ Additionally, $S_{n}=\left(I_{n}-\lambda_{0} W_{n}\right), S_{n}(\lambda)=\left(I_{n}-\lambda W_{n}\right)$ and we define $\varepsilon_{n}(\theta)=S_{n}(\lambda) W_{n} Y_{n}-X_{n} \beta$ for any value of $\theta$. Finally, for any square matrix $A_{n}$, we define $A_{n}^{s}=A_{n}+A_{n}^{\prime}$. This last notation is used in the expressions for identification and asymptotic distribution.

Lin \& Lee (2010) show that the (quasi-) maximum likelihood estimator of model (1) is generally inconsistent in presence of unknown heteroskedasticity. Alternative estimation methods are thus required. The Two-Stage Least Squares (2SLS) approach (Kelejian \& Prucha 1998), the Best 2SLS (Lee 2003) and the series Best 2SLS (Kelejian et al. 2004) could be considered, but according to Kelejian \& Prucha (2010, p.60), the asymptotic normality is not guaranteed under unknown heteroskedasticity. Kelejian \& Prucha (2010) generalize the method introduced in Kelejian \& Prucha (1999) to estimate a SAR model with SAR disturbances in the presence of unknown heteroskedasticity. They combine a generalized method of moments estimator (GMME) for the coefficient of spatial autocorrelation in the error term to a 2SLSE for the coefficient $\lambda_{0}$ associated to the spatial lag.

In this paper, we apply the approach developed by Lin \& Lee (2010) to estimate (1). ${ }^{4}$ The advantage of GMM procedure over 2SLS is that the former remains consistent even if none of the explanatory variable is relevant (Lee 2007). Besides, 2SLS, as will be shown later on, only uses the information contained in the deterministic part of the reduced form of (1), leaving the information in the stochastic part of the reduced form unexploited. Hence, the GMME will be more efficient than the 2SLSE. Lin \& Lee (2010) generalize Lee (2007) and Liu et al. (2010) where the focus is on homoskedastic error terms. With that respect, the main differences in the estimation procedure

\footnotetext{
${ }^{3}$ In this paper, we note $\lambda_{0}$ and $\beta_{0}$ as the true value of the parameters, $\widehat{\lambda}$ and $\widehat{\beta}$ as estimators of $\lambda_{0}$ and $\beta_{0}$ and $\lambda$ and $\beta$ as parameters on which we maximize the objective function. Hence, only $\widehat{\lambda}$ and $\widehat{\beta}$ are viewed as random variables.

${ }^{4}$ The estimation procedure developed in Kelejian \& Prucha (2010) could also have been used since they use the same moment conditions as Lin \& Lee (2010).
} 
due to relaxing the homoskedasticity assumption come from the hypothesis on quadratic moments and the absence of a Best Optimal GMME (BOGMME).

The objective of this section is to present GMM estimation in the presence of unknown heteroskedasticity. The set of assumptions presented below corresponds to those developed in Lin \& Lee (2010) and are reproduced for the sake of readability of the paper.

Assumption 1 The $\varepsilon_{\text {in }}$ 's are independent $\left(0, \sigma_{i n}^{2}\right)$ with finite moments larger than the fourth order such that $\mathbf{E}\left|\varepsilon_{i n}\right|^{4+\eta}$ for some $\eta>0$ are uniformly bounded for all $n$ and $i$.

As orthogonality conditions require the computation of mean and variances of quadratic forms, one needs to impose the uniform boundedness of moments of order higher than 4 .

Assumption 2 The elements of the $n \times k$ regressors matrix $X_{n}$ are uniformly bounded constants, $X_{n}$ has a full rank $k$ and $\lim _{n \rightarrow \infty} \frac{1}{n} X_{n}^{\prime} X_{n}$ exists and is nonsingular.

Assumption 3 The interaction matrices $W_{n}$ and the matrix $S_{n}^{-1}$ are uniformly bounded in absolute value in both row and column sums.

Assumption 3 means that the inverse of $S_{n}=I_{n}-\lambda_{0} W_{n}$ should be uniformly bounded in absolute value (in addition to $W_{n}$ ). It is important to note that the uniform boundedness is only imposed at the true parameter value and not for any value of $\lambda$. Assuming the existence of $S_{n}^{-1}$, the reduced form of model (1) is as follows

$$
Y_{n}=S_{n}^{-1} X_{n} \beta+S_{n}^{-1} \varepsilon_{n}
$$

where $S_{n}^{-1}=I_{n}+\lambda_{0} W_{n}+\lambda_{0}^{2} W_{n}^{2}+\cdots$.

From (2), we can express $W_{n} Y_{n}$ as follows:

$$
W_{n} Y_{n}=G_{n} X_{n} \beta_{0}+G_{n} \varepsilon_{n}
$$

with $G_{n}=W_{n} S_{n}^{-1}$. 


\subsection{Orthogonality conditions}

In general, $W_{n} Y_{n}$ is correlated with $\varepsilon_{n}$ since $\mathbf{E}\left(\left(W_{n} Y_{n}\right)^{\prime} \varepsilon_{n}\right)=\operatorname{tr}\left(\Sigma_{n} G_{n}\right) \neq 0$ where $\Sigma_{n}$ is a diagonal matrix containing the residual variance $\sigma_{i n}^{2}=\mathbf{E}\left(\varepsilon_{i n}^{2}\right)$ for $i=1, \ldots, n$. The GMM approach developed by Lin \& Lee (2010) combines linear moments (identical to 2SLS method) and quadratic moments. Let $Q_{n}$ be a $n \times k^{*}$ matrix of IV's, with $k^{*} \geq k+1$, which contains the information of the deterministic part $\mathbf{E}\left(W_{n} Y_{n} \mid X_{n}\right)$ of $W_{n} Y_{n}$ in (3). This matrix is constructed from $X_{n}$ and functions of $W_{n}$. It can be used to instrument $W_{n} Y_{n}$ and $X_{n}$. For instance, $Q_{n}=\left[X_{n}, W_{n} X_{n} W_{n}^{2} X_{n}, \cdots\right]_{L I}$, where $L I$ stands for linearly independent columns.

Lin \& Lee (2010) additionally consider quadratic moments $\left(P_{j n} \varepsilon_{n}(\theta)\right)^{\prime} \varepsilon_{n}(\theta)$ that capture the information contained in the stochastic part of (3). These quadratic moments serve as IV's for $G_{n} \varepsilon_{n}$, the non-deterministic part of $W_{n} Y_{n}$. One needs to impose some conditions on $P_{j n}$ matrices so that quadratic moments can act as orthogonality conditions $\left(\mathbf{E}\left[\varepsilon_{n}^{\prime} P_{j n}^{\prime} \varepsilon_{n}\right]=0\right)$, i.e. $P_{j n} \varepsilon_{n}$ is uncorrelated with $\varepsilon_{n}$. Let $\mathcal{P}_{1 n}$ be the class of constant $n \times n$ matrices with zero trace. Consider a subclass $\mathcal{P}_{2 n}$ of $\mathcal{P}_{1 n}$ that contains constant $n \times n$ matrices with zero diagonal. Depending on the assumptions made on the error term, matrices $P_{j n}$ may belong to $\mathcal{P}_{1 n}$ or $\mathcal{P}_{2 n}$.

Let us consider heteroskedastic error terms with, as variance-covariance matrix, the diagonal matrix $\Sigma_{n}$, made of $\sigma_{i n}^{2}$, the individual variances. The orthogonality condition associated to a given matrix $P_{j n}$ is $\mathbf{E}\left(\varepsilon_{n}^{\prime} P_{j n}^{\prime} \varepsilon_{n}\right)=\operatorname{tr}\left(\Sigma_{n} P_{j n}\right)$. The only way for this trace to be 0 is that $P_{j n} \in \mathcal{P}_{2 n}$. The intuition is that when $P_{j n}$ has zero diagonal, the $l^{\text {th }}$ element of $P_{j n} \varepsilon_{n}=\sum_{k=1}^{n} p_{l k, j n} \varepsilon_{k n}$ excludes the corresponding element of $\varepsilon_{n}\left(\varepsilon_{l n}\right)$ from the sum since $p_{l l, j n}=0$. So, each component of $P_{j n} \varepsilon_{n}$ is uncorrelated with the corresponding component of $\varepsilon_{n}$. Imposing homoskedasticity of the error term, $\mathbf{E}\left(\varepsilon_{n}^{\prime} P_{j n}^{\prime} \varepsilon_{n}\right)=\sigma_{0}^{2} \operatorname{tr}\left(P_{j n}\right)$. Hence, $P_{j n}$ is only required to have a zero trace for this expression to be null (Lee 2001, 2007).

However, no matter the hypothesis on the variance of the error term, we need $P_{j n} \varepsilon_{n}$ to be correlated with $W_{n}\left(I_{n}-\lambda_{0} W_{n}\right)^{-1}$ for $P_{j n} \varepsilon_{n}$ to act as an instrument for $G_{n} \varepsilon_{n}$ and the closest $P_{j n}$ is of $W_{n}\left(I_{n}-\lambda_{0} W_{n}\right)^{-1}$, the better the instrument. 
Quadratic moments are used for 2 reasons. As they capture the information contained in the stochastic part of (3), they make the obtained estimator more efficient compared to 2SLS or B2SLS estimators. Second, if all $X_{n}$ are irrelevant, linear moments can not be used to instrument $W_{n} Y_{n}$. However, in that case, which corresponds to the pure SAR model, i.e. $Y_{n}=\lambda W_{n} Y_{n}+\varepsilon_{n}$, quadratic moments can still act as instruments for $W_{n} Y_{n}$.

Assumption 4 The matrices $P_{n, j}$ 's whose diagonal elements are $0\left(P_{n, j} \in \mathcal{P}_{n 2}\right)$ are uniformly bounded in both row and column sums, and elements of $Q_{n}$ are uniformly bounded.

Under heteroskedasticity, the set of moment functions, assuming $m$ quadratic moments, is:

$$
\begin{aligned}
g_{n}(\theta) & =\left(P_{1 n} \varepsilon_{n}(\theta), \cdots, P_{m n} \varepsilon_{n}(\theta), Q_{n}\right)^{\prime} \varepsilon_{n}(\theta) \\
& =\left(\varepsilon_{n}(\theta)^{\prime} P_{1 n} \varepsilon_{n}(\theta), \cdots, \varepsilon_{n}(\theta)^{\prime} P_{m n} \varepsilon_{n}(\theta), \varepsilon_{n}(\theta)^{\prime} Q_{n}\right)^{\prime}
\end{aligned}
$$

\section{$2.2 \quad$ Asymptotic properties}

Assumption 5 ensures the identification of $\theta_{0}$ from the orthogonality conditions $E\left(g_{n}\left(\theta_{0}\right)\right)=0$, for a sufficiently large $n$.

\section{Assumption 5 Either:}

a) $\lim _{n \rightarrow \infty} \frac{1}{n} Q_{n}^{\prime}\left(G_{n} X_{n} \beta_{0}, X_{n}\right)$ has the full rank $k+1$, or

b) $\lim _{n \rightarrow \infty} \frac{1}{n} Q_{n}^{\prime} X_{n}$ has the full rank $k, \lim _{n \rightarrow \infty} \frac{1}{n} \operatorname{tr}\left(\Sigma_{n} G_{n}^{s} P_{j n}\right) \neq 0$ for some $j$ and $\lim _{n \rightarrow \infty} \frac{1}{n}\left(\operatorname{tr}\left(\Sigma_{n} G_{n}^{\prime} P_{1 n} G_{n}\right), \cdots, \operatorname{tr}\left(\Sigma_{n} G_{n}^{\prime} P_{m n} G_{n}\right)\right)^{\prime}$ are linearly independent.

Assumption 6 focuses on the parameter space for $\theta$.

Assumption $6 \theta_{0}$ is in the interior of the parameter space $\Theta$, which is a bounded subset of $\mathcal{R}^{k+1}$.

By contrast to maximum likelihood estimation, $\lambda$ is not required to belong to some compact 
parameter space. ${ }^{5}$ The constraints imposed on the parameter space ensure the positiveness of the Jacobian of the transformation $\left|I_{n}-\lambda W_{n}\right|$. However, in the GMM framework, such constraints are not relevant because the objective function is a polynomial function (of order 4 ) in $\theta$. The condition on the boundedness of the parameter space is solely for the theoretical purpose of proving consistency of the GMME (Lin \& Lee 2010). Hence, the GMM is a unconstrained estimation procedure.

Instead of minimizing the objective function $g_{n}(\theta)^{\prime} g_{n}(\theta)$ with respect to $\theta$, Lin \& Lee $(2010)$ propose to minimize a linear combination $a_{n} g_{n}(\theta)$ of the moment functions $g_{n}(\theta)$, so that the objective function enters the Hansen (1982) setting where each condition is weighted by its precision. The matrix $a_{n}$ has a full rank greater than or equal to the dimension of $\theta$. The objective function is thus $g_{n}(\theta)^{\prime} a_{n}^{\prime} a_{n} g_{n}(\theta)$ where the matrix $a_{n}^{\prime} a_{n}$ is non-negative and contains the weight of each orthogonality condition and motivates the issue of optimal weighting.

To express the asymptotic distribution of the Robust (to the presence of unknown heteroskedasticity) GMME, we need the expression of the gradient of $g_{n}\left(\theta_{0}\right)$ as well as the variance matrix of the orthogonality conditions (also evaluated at the true parameters values):

$$
\begin{aligned}
& D_{n}=\frac{\partial \mathbf{E}\left(g_{n}\left(\theta_{0}\right)\right)}{\partial \theta^{\prime}}=-\left(\begin{array}{cc}
\operatorname{tr}\left(\Sigma_{n} P_{1 n}^{s} G_{n}\right) & 0 \\
\vdots & \vdots \\
\operatorname{tr}\left(\Sigma_{n} P_{m n}^{s} G_{n}\right) & 0 \\
Q_{n}^{\prime} G_{n} X_{n} \beta_{0} & Q_{n}^{\prime} X_{n}
\end{array}\right) \\
& \Omega_{n}=\operatorname{Var}\left(g_{n}\left(\theta_{0}\right)\right)=\left(\begin{array}{cccc}
\operatorname{tr}\left(\Sigma_{n} P_{n, 1}\left(\Sigma_{n} P_{1 n}\right)^{s}\right) & \operatorname{tr}\left(\Sigma_{n} P_{1 n}\left(\Sigma_{n} P_{2 n}\right)^{s}\right) & \cdots & 0 \\
\operatorname{tr}\left(\Sigma_{n} P_{n, 2}\left(\Sigma_{n} P_{1 n}\right)^{s}\right) & \operatorname{tr}\left(\Sigma_{n} P_{2 n}\left(\Sigma_{n} P_{2 n}\right)^{s}\right) & \cdots & 0 \\
\vdots & \vdots & & \vdots \\
0 & 0 & \cdots & Q_{n}^{\prime} \Sigma_{n} Q_{n}
\end{array}\right)
\end{aligned}
$$

Lin \& Lee (2010) show that under Assumptions 1-6, and that $\lim _{n \rightarrow \infty} \frac{1}{n} a_{n} D_{n}$ exists and has the

\footnotetext{
${ }^{5}$ For more information about the parameter space for $\lambda$, the interested reader may consult Kelejian \& Prucha (2010).
} 
full rank $k+1$, the Robust GMME $\widehat{\theta}$ is a consistent estimator of $\theta_{0}$ and $\sqrt{n}\left(\widehat{\theta}-\theta_{0}\right) \stackrel{D}{\rightarrow} N(0, \Gamma)$, where

$$
\Gamma=\lim _{n \rightarrow \infty}\left(\frac{1}{n} D_{n}^{\prime} a_{n}^{\prime} a_{n} D_{n}\right)^{-1} D_{n}^{\prime} a_{n}^{\prime} a_{n} \Omega_{n} a_{n}^{\prime} a_{n} D_{n}\left(D_{n}^{\prime} a_{n}^{\prime} a_{n} D_{n}\right)^{-1}
$$

\subsection{Optimal RGMME}

Even though the choice of the weighting matrix $a_{n}^{\prime} a_{n}$ does not affect the consistency of RGMME, it plays a role in its efficiency. By setting $a_{n}^{\prime} a_{n}$ equal to the inverse of the covariance matrix of orthogonality conditions $\left(\Omega_{n}\right)$, one obtains the optimal RGMME, i.e. the most efficient estimator given $g_{n}(\theta)$. In their proposition 3 , Lin \& Lee (2010) show that if one has a consistent estimator $\widehat{\Omega}_{n}$, the asymptotic distribution of the feasible "optimal" RGMME obtained from minimizing $g_{n}(\theta)^{\prime} \widehat{\Omega}_{n} g_{n}(\theta)$ with respect to $\theta$ is as follows:

$$
\sqrt{n}\left(\widehat{\theta}-\theta_{0}\right) \stackrel{D}{\rightarrow} N\left(0,\left(\lim _{n \rightarrow \infty} \frac{1}{n} D_{n}^{\prime} \widehat{\Omega}_{n}^{-1} D_{n}\right)^{-1}\right)
$$

The optimal estimator is the most efficient estimator that can be obtained given a set of orthogonality conditions. However, we could question the existence of the best choice of orthogonality conditions, i.e. the set of conditions which guarantees that the best optimal RGMME is the most efficient one. Unfortunately, in the unknown heteroskedasticity case, no such set of orthogonality conditions exists, since they would involve the unknown $\Sigma_{n}$. However, Lin \& Lee (2010) suggest to use as orthogonality conditions those corresponding to the best conditions in the iid case when $P_{j n} \in \mathcal{P}_{n, 2}$. These conditions, shown in Lee $(2007)$, are $P_{n}=\left(G_{n}-\operatorname{Diag}\left(G_{n}\right)\right)$ and $Q_{n}=\left[G_{n} X_{n} \beta_{0}, X_{n}\right]$, where $\operatorname{Diag}\left(A_{n}\right)$ refers to a diagonal matrix where diagonal elements correspond to the diagonal of $A_{n} \cdot{ }^{6}$ Hence, they suggest to use only one quadratic and $k+1$ linear conditions. The vector of orthogonality conditions becomes:

$$
g_{n}(\theta)=\left(\varepsilon_{n}^{\prime}(\theta) P_{n} \varepsilon_{n}(\theta), \varepsilon_{n}^{\prime} Q_{n}\right)^{\prime}
$$

\footnotetext{
${ }^{6}$ If quadratic moments $P_{n}$ belong to $\mathcal{P}_{n 1}$, Liu et al. (2010) derive the best moment conditions under homoskedasticity, no matter the distribution of the error terms.
} 
Expressions for the gradient and the covariance matrix of $g_{n}(\theta)$ defined in $(9)$, evaluated at the true parameter value are:

$$
\begin{aligned}
& D_{n}=-\frac{\partial \mathbf{E}\left(g_{n}\left(\theta_{0}\right)\right)}{\partial(\theta)}=\left(\begin{array}{cc}
\operatorname{tr}\left(P_{n}^{s} G_{n} \Sigma_{n}\right) & 0 \\
Q_{n}^{\prime} G_{n} X_{n} \beta_{0} & Q_{n}^{\prime} X_{n}
\end{array}\right) \\
& \Omega_{n}=\operatorname{Var}\left(g_{n}\left(\theta_{0}\right)\right)=\left(\begin{array}{cc}
\operatorname{tr}\left(\Sigma_{n} P_{n}\left(\Sigma_{n} P_{n}\right)^{s}\right) & 0 \\
0 & Q_{n}^{\prime} \Sigma_{n} Q_{n}
\end{array}\right)
\end{aligned}
$$

As these orthogonality conditions depend on the unknown parameters $\lambda_{0}$ and $\beta_{0}$, we need to proceed in 2 steps to get the optimal RGMME. The first stage consists in getting consistent estimators of $\lambda_{0}$ and $\beta_{0}$. To do so, we compute RGMME based on orthogonality conditions not involving any unknown parameters but which satisfy the above assumptions. For instance, we set $P_{n}=W_{n}$ and $Q_{n}=\left[X_{n}, W_{n} X_{n}, W_{n}^{2} X_{n}\right]$. Also we use as initial guess of the weight matrix $a_{n}^{\prime} a_{n}$ the identity matrix. The obtained (first-step) estimators, $\check{\lambda}^{f s}$ and $\breve{\beta}^{f s}$, are then used to compute the residuals which allow to have an estimator $\breve{\Sigma}_{n}$, whose $\mathrm{i}^{\text {th }}$ diagonal element is $\check{\varepsilon}_{\text {in }}^{2}(\check{\theta})$. We are now able to compute an estimator $\check{\Omega}_{n}$ of $\Omega_{n}$. Besides, we can construct the new orthogonality conditions $g_{n}^{s t}=\left(\varepsilon_{n}^{\prime}(\theta) P_{n}^{s t} \varepsilon_{n}(\theta), \varepsilon_{n}^{\prime}(\theta) Q_{n}^{s t}\right)^{\prime}$ based on $P_{n}^{s t}=\left(\breve{G}_{n}-\operatorname{Diag}\left(\breve{G}_{n}\right)\right)$ and $Q_{n}^{s t}=\left[\breve{G}_{n} X_{n} \breve{\beta}^{f s}, X_{n}\right]$, where $\check{G}_{n}=W_{n}\left(I_{n}-\check{\lambda}^{f s} W_{n}\right)^{-1}$.

The second steps consists in minimizing the objective function shown in (12) with respect to $\theta$ :

$$
g_{n}^{s t}(\theta)^{\prime} \check{\Omega}_{n}^{-1} g_{n}^{s t}(\theta)
$$

Statistical inference will be based on this second step estimator $\widehat{\theta}$, which has an estimated asymptotic covariance matrix equal to $\left(\frac{1}{n} \widehat{D}_{n}^{\prime} \widehat{\Omega}_{n}^{-1} \widehat{D}_{n}\right)^{-1}$. In this expression, $\widehat{D}_{n}$ is constructed from plugging the second step estimators within equation (10) and $\widehat{\Omega}_{n}$ comes from plugging the second step estimators in equation (11). 


\section{Interpretation of the SAR model}

Let us now consider the interpretation of the estimation results of the heteroskedastic SAR model in terms of the impact of a variation of an independent variable on the dependent variable. As the model is estimated in implicit form (1), we need to rely on its reduced form to provide economic interpretations. The reduced form in (2) can be explicitly written as follows:

$$
Y_{n}=\sum_{h=1}^{k} \beta_{0, h}\left(I_{n}-\lambda_{0} W_{n}\right)^{-1} X_{n, h}+\left(I_{n}-\lambda_{0} W_{n}\right)^{-1} \varepsilon_{n}
$$

Taking the first order partial derivatives of $Y_{n}$ with respect to $X_{n, h}$, for $h=1, \ldots, k$, we then obtain, the so-called $(n \times n)$ impact matrices, one for each of the $k$ explanatory variables:

$$
\Xi_{n}^{(h)}=\frac{\partial Y_{n}}{\partial X_{n, h}^{\prime}}=\beta_{0, h}\left(I_{n}-\lambda_{0} W_{n}\right)^{-1}=\beta_{0, h} \sum_{v=0}^{\infty} \lambda_{0}^{v} W_{n}^{v}=\beta_{0, h}\left(I_{n}+\lambda_{0} W_{n}+\lambda_{0}^{2} W_{n}^{2}+\lambda_{0}^{3} W_{n}^{3}+\ldots\right)
$$

where $\left(I_{n}-\lambda_{0} W_{n}\right)^{-1}$ is the so-called global interaction multiplier. ${ }^{7}$ Note that the impact matrices are generally full and not symmetric regardless of the sparsity and structure of the interaction matrix $W_{n}$. We call the country in column $j$ of this matrix the emitting country and country in row $i$ the receiving country.

For the explanatory variable $X_{h}$, the diagonal elements of the impact matrix, specified in equation (14), which we call the direct impacts, are heterogeneous in presence of spatial autocorrelation due to higher order feedback effects. More precisely, the own derivative for country $i$ includes feedback effects where country $i$ affects country $j$ and country $j$ also affects country $i$ as well as longer paths which might go from country $i$ to $j$ to $k$ and back to $i$. This is what Debarsy \& Ertur (2010) call interactive heterogeneity, by contrast to standard individual heterogeneity in panel data

\footnotetext{
${ }^{7}$ To empirically compute expression (14), we have to replace the true values of the parameters by their estimated counterparts.
} 
models. $^{8}$

$$
\operatorname{Diag}\left(\Xi_{n}^{(h)}\right)=\beta_{0, h} I_{n}+\beta_{0, h} \operatorname{Diag}\left(\lambda_{0}^{2} W_{n}^{2}+\lambda_{0}^{3} W_{n}^{3}+\ldots\right)
$$

The magnitude of those direct effects mostly depends on the value of $\beta_{0, h}$, which is constant across the sample. Heterogeneity thus comes from the second term on the right hand side of equation (15) representing the magnitude of pure feedback effects, which depends again on $\beta_{0, h}$, on the values of powers of $\lambda_{0}$, and on the interconnection structure of the observations embedded in the powers of the interaction matrix $W_{n}$. It is nevertheless likely to be negligible compared to the value of $t \beta_{0, h}$ in most of applied works.

However the main question in this type of spatial econometric specification concerns the impact of a variation of an explanatory variable in a country $i$ on the dependent variable in other countries of the sample, which we call the indirect effects, i.e. the off-diagonal terms of the impact matrix, and which represent the spillovers. They are presented in expression (16):

$$
\Xi_{n}^{(h)}-\operatorname{Diag}\left(\Xi_{n}^{(h)}\right)=\beta_{0, h} \lambda_{0} W_{n}+\beta_{0, h}\left[\lambda_{0}^{2} W_{n}^{2}-\operatorname{Diag}\left(\lambda_{0}^{2} W_{n}^{2}\right)\right]+\beta_{0, h}\left[\lambda_{0}^{3} W_{n}^{3}-\operatorname{Diag}\left(\lambda_{0}^{3} W_{n}^{3}\right)\right]+\ldots
$$

By contrast to direct effects, the main part is played here by the informational content and the structure of the interaction matrix $W_{n}$, which is the main source of heterogeneity, parameters $\lambda_{0}$ and $\beta_{0, h}$ being constant across the whole sample. Again, high order terms in the infinite sum in (16) may be negligible compared to the values of $W_{n}$. Not surprisingly, strongly connected countries are more impacted than less connected countries. However, spillovers diffuse to the entire sample.

Finally, the sum of the $i^{\text {th }}$ row of the impact matrix (14) represents the total impact on the dependent variable in country $i$ due to a 1 unit change in $X_{n, h}$ in each of the countries in the sample. The sum of column $j$ gives the total impact on the dependent variable of all the countries of a 1 unit change of $X_{n, h}$ in country $j$, which is of particular interest in terms of interpretation

\footnotetext{
${ }^{8}$ We call those effect directs impacts since we compute the impact of the variation of an explanatory variable in country $i$, the emitting country on itself.
} 
here.

\section{The modified $J$ test based on RGMM}

For ease of exposition, let us consider that under the null hypothesis $H_{0}$ and the $M-1$ alternative hypotheses $H_{1, m}, m=2, \ldots, M$, we have heteroskedastic SAR models which only differ by the specification of the interaction matrix.

$$
\begin{gathered}
H_{0}: Y_{n}=X_{n} \beta_{1}+\lambda_{1} W_{1 n} Y_{n}+\varepsilon_{1 n}, \\
H_{1, m}: Y_{n}=X_{n} \beta_{m}+\lambda_{m} W_{m n} Y_{n}+\varepsilon_{m n},
\end{gathered}
$$

The general motivation of the $J$ test is to estimate a model which contains the null model and the predictive power of alternative models in order to check if predictors from alternative models can significantly contribute to the explanatory power in the null model. For the homoskedastic case, different predictors have been derived by Kelejian \& Prucha (2007) which are presented here for the sake of comparison with the heteroskedastic case. The first predictor $\widehat{y}_{i n \mid 1}^{m}$ is obtained from the reduced form of the alternative model $m$ :

$$
\begin{aligned}
\widehat{y}_{i n \mid 1}^{m} & =\mathbf{E}\left(y_{i n} \mid \Lambda_{1}\right) \\
& =\left(I_{n}-\lambda_{m} W_{m n}\right)_{i .}^{-1} X_{n} \beta_{m}
\end{aligned}
$$

where $A_{i}$. means the $i^{\text {th }}$ row of matrix A. This predictor is based on the smallest information set, namely $\Lambda_{1}=\left\{X, W_{m n}\right\}$. The second predictor is based on a larger information set, namely $\Lambda_{2}=\left\{X, W_{m n}, W_{m n, i .} Y_{n}\right\}$. It is obtained form the structural form of the alternative model $m$ and 
is computed as follows:

$$
\begin{aligned}
\widehat{y}_{i n \mid 2}^{m} & =\mathbf{E}\left(y_{i n} \mid \Lambda_{2}\right) \\
& =\lambda_{m} W_{m n, i .} Y_{n}+X_{i ., n} \beta_{m}+\frac{\operatorname{cov}\left(\varepsilon_{i n}, W_{m n, i .} Y_{n}\right)}{\operatorname{var}\left(W_{m n, i .} Y_{n}\right)}\left[W_{m n, i .} Y_{n}-\mathbf{E}\left(W_{m n, i .} Y_{n}\right)\right]
\end{aligned}
$$

where $W_{m n, i}$. is the $\mathrm{i}^{t h}$ row of $W_{m n}$. Also, the last term takes into account the correlation between the error term and the spatial lag of the dependent variable. The different elements involved in this correlation are computed as follows:

$$
\begin{aligned}
\mathbf{E}\left(W_{m n, i .} Y_{n}\right) & =W_{m n, i .}\left(I-\lambda_{m} W_{m n}\right)^{-1} X_{n} \beta_{m} \\
\Sigma_{m}^{y} & =\left(I-\lambda_{m} W_{m n}\right)^{-1}\left(I-\lambda_{m} W_{m n}^{\prime}\right)^{-1} \\
\operatorname{var}\left(W_{m n, i .} Y_{n}\right) & =\sigma_{n}^{2} W_{m n, i .} \Sigma_{m}^{y} W_{m n, i .}^{\prime} \\
\operatorname{cov}\left(\varepsilon_{i n}, W_{m n, i .} Y_{n}\right) & =\sigma_{n}^{2}\left(I-\lambda_{m} W_{m n}^{\prime}\right)^{-1} X_{n} \beta_{m}
\end{aligned}
$$

where $\sigma_{n}^{2}$ is the variance of the error term in the homoskedastic case. Since the second information set is larger than the first one, the second predictor is more efficient (Kelejian \& Prucha 2007). A third predictor is sometimes considered due to its intuitive appeal. It is also based on the information set $\Lambda_{2}$ but assumes a zero correlation between the error term and the spatial lag of the dependent variable:

$$
\widehat{y}_{i n \mid 3}^{m}=\lambda_{m} W_{m n, i .} Y_{n}+X_{i ., n} \beta_{m}
$$

Kelejian \& Prucha (2007) show that it is biased since the spatial lag is assumed independent of the error term. We will thus do not consider it. ${ }^{9}$

Let us now study the predictors in the heteroskedastic case. Theoretically, we can use the first two predictors above. The first one, $\widehat{y}_{i n \mid 1}^{m}$, is not affected by the presence of heteroskedasticity and takes the same expression as for homoskedastic errors (equation 19). However, for the second predictor, $\widehat{y}_{i n \mid 2}^{m}$, the variance of the spatial lag and the covariance between the spatial lag and the

\footnotetext{
${ }^{9}$ Finally, Kelejian \& Prucha (2007) propose the full information predictor but it is not more efficient than the second for the SAR specification.
} 
error term have to be adapted for heteroskedasticity. They are presented in expression (22),

$$
\begin{aligned}
\operatorname{var}\left(W_{m n, i .} Y_{n}\right) & =\sigma_{i, m n}^{2} W_{m, i .} \Sigma_{m}^{y} W_{m n, i .}^{\prime} \\
\operatorname{cov}\left(\varepsilon_{i n}, W_{m n, i .} Y_{n}\right) & =\sigma_{i, m n}^{2}\left(I-\lambda_{m} W_{m n}^{\prime}\right)^{-1} X_{n} \beta_{m}
\end{aligned}
$$

where $\sigma_{i, m n}^{2}$ is the variance of the error term of individual $i$ in model $m$. The drawback of this predictor is that it involves the terms $\sigma_{i, m n}^{2}$ which are evaluated by computing $\widehat{\varepsilon}_{i, m n}^{2}$ but cannot be consistently estimated. However, even though $\Lambda_{1}$ is smaller than $\Lambda_{2}$, we show in section 4.2 below, using Monte Carlo experiments, that the first predictor should be preferred over the second to construct the $J$ test. In the following, we will thus only consider the first predictor for the sake of clarity. ${ }^{10}$

Let us denote $\widehat{Y}_{n}^{M}=\left[\widehat{y}_{n}^{2}, \ldots, \widehat{y}_{n}^{M}\right]$, the $n \times(M-1)$ matrix containing the $M-1$ predicted alternative models using the first predictor. We then augment the model under the null (model 17) with the predictors $\widehat{Y}_{n}^{M}$ :

$$
Y_{n}=X_{1 n} \beta_{1}+\lambda_{1} W_{1 n} Y_{n}+\widehat{Y}_{n}^{M} \delta+\varepsilon_{1 n}
$$

where $\delta$ is a $(M-1) \times 1$ vector of parameters: $\delta^{\prime}=\left[\delta_{2}, \ldots, \delta_{M}\right]$. If the model under the null is the correct model, then: $\delta$ should not significantly differ from 0 . This is the $J$ test.

Our $J$ test procedure based on the RGMM estimation procedure is summarized in the following steps:

Step 1: Estimate the parameters $\beta_{m}$ and $\lambda_{m}$ for $m=2, \cdots, M$ by the two-step optimal RGMM approach described in section 2 .

Step 2: Estimate $\widehat{y}_{n}^{m}$ for $m=2, \cdots, M$ and form $\widehat{Y}_{n}^{M}=\left[\widehat{y}_{n}^{2}, \ldots, \widehat{y}_{n}^{M}\right]$.

Step 3: Estimate the augmented model $Y_{n}=X_{n} \beta_{1}+\lambda_{1} W_{1 n} Y_{n}+\widehat{Y}_{n}^{M} \delta+\varepsilon_{1 n}$ by the two-step optimal RGMM approach described in section 2.

\footnotetext{
${ }^{10}$ The computation of the $J$ test and the $M J$ test are not affected by using the second predictor.
} 
Note that the predicted values do not add any difficulties to the model and are simply included in the set of exogenous variables : $\tilde{X}=\left[X, \widehat{Y}_{n}^{M}\right]$ (see Davidson \& MacKinnon 1981, p.785).

Step 4: Construct the $J$ test

Define $\gamma_{1}=\left(\beta_{1}^{\prime}, \lambda_{1}, \delta^{\prime}\right)^{\prime}$. Let $R=\left(0_{(M-1) \times\left(k_{1}+1\right)}, I_{(M-1)}\right)$ so that $R \gamma_{1}=0$. Then, the $J$ statistic defined as a Wald statistic is:

$$
J_{1, n}=\left(R \widehat{\gamma}_{1}\right)^{\prime}\left[R\left(\widehat{D}_{n}^{\prime}\left(\widehat{\Omega}_{n}^{-1}\right) \widehat{D}_{n}\right)^{-1} R^{\prime}\right]^{-1}\left(R \widehat{\gamma}_{1}\right) \sim \chi^{2}(M-1)
$$

where $\widehat{D}_{n}^{\prime}$ and $\widehat{\Omega}_{n}^{-1}$ are respectively the gradient and the inverse of the covariance matrix of the augmented two-step RGMM estimation procedure. In this paper, we follow Davidson \& Mackinnon (1985) who suggest to use the variance-covariance of the augmented specification. $^{11}$

\subsection{Statistical inference based on bootstrap}

Davidson \& MacKinnon (2002) show that statistical inference based on asymptotic theory causes size distortion of the $J$ test while a bootstrap approach performs better in small sample sizes. Burridge \& Fingleton (2010) implement a semi-parametric bootstrap approach to the $J$ test applied to the choice of the interaction matrix in spatial econometrics. ${ }^{12}$ They show that statistical inference based on bootstrap outperforms statistical inference based on asymptotic distribution for the $J$ statistic. Besides, Jin \& Lee (2015) formally prove the consistency of the bootstrap approach in spatial econometrics for linear-quadratic forms of residuals test-statistics, such as Moran's I or $J$ test. In this paper, to account for heteroskedasticity, we follow Hagemann (2012) and implement the wild bootstrap of Liu (1988) and Mammen (1992). It consists in perturbing the residuals

\footnotetext{
${ }^{11}$ Alternatively, Davidson \& Mackinnon (1985) also suggest to use the estimated covariance matrix coming from the estimation of the model under the null hypothesis. However, the Monte Carlo simulations we performed indicate poor performance of this alternative method.

${ }^{12}$ Burridge \& Fingleton (2010) consider a homoskedastic error term, a first step estimation procedure based on maximum likelihood and an augmented model estimated by IV. We differ from that paper by allowing unknown heteroskedasticity in the error term and estimating all models by Robust GMM.
} 
with iid copies $\eta_{1}, \eta_{2}, \cdots, \eta_{n}$ of a random variable $\eta$ with $\mathbf{E}(\eta \mid y, \mathcal{F})=0, \mathbf{E}\left(\eta^{2} \mid y, \mathcal{F}\right)=1$ and $\mathbf{E}\left(|\eta|^{2+\zeta} \mid y, \mathcal{F}\right)<\infty$ for some $\zeta>0$. Hagemann (2012), following Davidson \& Flachaire (2008), recommends the use of a Rademacher distribution for $\eta$ that takes on the value 1 with probability 0.5 and -1 with probability 0.5 . Finally, let $H$ be a diagonal matrix having as diagonal elements the terms $\eta_{1}, \eta_{2}, \cdots, \eta_{n}$.

Consider model (17) as the model under the null

i) Compute the $J$ test associated to this model using the methodology presented above and label it $\widehat{J}_{1, n}$.

ii) Estimate model (17) to get $\widehat{\beta}_{1}, \widehat{\lambda}_{1}$ and the residuals $\widehat{\varepsilon}_{1 n}$

iii) Generate $\varepsilon_{1 n}^{*}=H \widehat{\varepsilon}_{1 n}$

$i v)$ Generate the bootstrapped sample $Y_{n}^{*}=\left(I_{n}-\widehat{\lambda}_{1} W_{1 n}\right)^{-1}\left[X_{n} \widehat{\beta}_{1}+\varepsilon_{1 n}^{*}\right]$

$v$ ) Compute the bootstrapped $J$ test for the model (17) using the bootstrapped dependent variable $Y_{n}^{*}$ and label it $J_{1, n}^{*}$.

Repeat operations $i i$ ) to $v$ ) B times, each with a new realization of $H$. Reject the null hypothesis at the $\alpha$ threshold if $\widehat{J}_{1, n}$ is larger than $c_{1-\alpha}^{*}$, the $1-\alpha$ empirical quantile of the distribution of $J_{1, n}^{*}$.

\subsection{Monte Carlo experiments}

In this section, we perform Monte Carlo experiments to compare the small sample properties of the $J$ test using the first or the second predictor. Theoretically, even though the information set for the second predictor (based on the structural form) is larger than for the first predictor (based on the

reduced form), we have seen that the former requires the estimation of $\sigma_{i}^{2}$ for which no consistent estimator exists. The objective of these Monte Carlo experiments is to assess the importance of this drawback in small samples.

We consider the following DGP: 


$$
Y_{n}=\lambda W_{n} Y_{n}+\beta_{0} \iota_{n}+X_{1 n} \beta_{1}+X_{2 n} \beta_{2}+\varepsilon_{n}
$$

where $\iota_{n}$ is the unit vector, $X_{1 n} \sim U(0,10), X_{2 n} \sim N(0,1)$ and the associated vector of parameters $\beta_{0}, \beta_{1}$ and $\beta_{2}$ are all set equal to 1 . In these simulations, the regressors are kept constants across replications. The error term is assumed heteroskedastic and non-normally distributed. More precisely, it is designed in the following way:

$$
\varepsilon_{i n}=\bar{\sigma}\left(\frac{\nu_{i n}-2}{\sqrt{2}}\right) X_{i, 1 n}
$$

where $\nu_{\text {in }}$ follows a $\Gamma(2,1)$ distribution. Besides, to make simulation results comparable across different values of parameters, we set the average dispersion of the error term $(\bar{\sigma})$ so that the signal to noise ratio is equal to 0.6. This signal to noise ratio is computed as the ratio of the explained variance over the total variance, ignoring spatial autocorrelation (see Lee 2007, Liu et al. 2010). This ratio would correspond to a goodness of fit of 0.6 in a standard regression.

The spatial autoregressive parameter $\lambda$ varies from 0.2 to 0.8 by increment of 0.2 to capture low, moderate and high spatial autocorrelation. Two sample sizes, $n=100$ and $n=254$, are considered, corresponding respectively to the number of counties in North Carolina and in Texas. We use different interaction matrices $W_{n}$ to cover sparse and dense interaction schemes. Definition of the $W_{n}$ considered is given in Table 1. Finally, for each case, we perform 1000 replications.

\begin{tabular}{|c|c|}
\hline Name & Expression \\
\hline Inverse exponential distance & $w_{i j}=e^{-d_{i j}}$ \\
\hline Inverse square distance & $w_{i j}=1 / d_{i j}^{2}$ \\
\hline $5 n n$. & $w_{i j}=\left\{\begin{array}{l}1 \text { if } j \text { is in the } 5 \mathrm{nn} . \text { of } i \\
0 \text { otherwize }\end{array}\right.$ \\
\hline 20 nn. & $w_{i j}=\left\{\begin{array}{l}1 \text { if } j \text { is in the } 20 \mathrm{nn} . \text { of } i \\
0 \text { otherwize }\end{array}\right.$ \\
\hline
\end{tabular}

Table 1: Definition of the interaction matrices

Note: The distance between 2 observations is computed as the geodesic distance and $n n$. stands for nearest neighbors.

Tables 2 and 3 compare the performance in terms of rejection rate of the $J$ test when constructed 
Table 2: Comparison of $J$ test performance for the 2 predictors, $n=100$ First Predictor

Second Predictor

\begin{tabular}{|c|c|c|c|c|c|c|c|c|}
\hline \multirow[b]{3}{*}{$\lambda$} & \multicolumn{4}{|c|}{ First Predictor } & \multicolumn{4}{|c|}{ Second Predictor } \\
\hline & \multicolumn{2}{|c|}{ Rej. Rate $J$ test M1 } & \multicolumn{2}{|c|}{ Rej. Rate $J$ test M2 } & \multicolumn{2}{|c|}{ Rej. Rate $J$ test M } & \multicolumn{2}{|c|}{ Rej. Rate $J$ test M2 } \\
\hline & Boot. & Asymp. & Boot. & Asymp. & Boot. & Asymp. & & Asymp. \\
\hline & \multicolumn{8}{|c|}{ A) $\mathrm{M} 1: \mathrm{W}=5$ nearest neighbors ; $\mathrm{M} 2: \mathrm{W}=20$ nearest neighbors } \\
\hline 0.2 & 0.047 & 0.048 & 0.416 & 0.443 & 0.069 & 0.328 & 0.116 & 0.401 \\
\hline 0.4 & 0.045 & 0.050 & 0.916 & 0.941 & 0.057 & 0.260 & 0.521 & 0.884 \\
\hline 0.6 & 0.049 & 0.055 & 0.995 & 0.996 & 0.050 & 0.232 & 0.923 & 0.993 \\
\hline \multirow[t]{2}{*}{0.8} & 0.050 & 0.065 & 0.989 & 0.996 & 0.052 & 0.311 & 0.998 & 0.999 \\
\hline & \multicolumn{8}{|c|}{ B) $\mathrm{M} 1: \mathrm{W}=5$ nearest neighbors ; $\mathrm{M} 2: \mathrm{W}=$ Exponential inverse distance } \\
\hline 0.2 & 0.039 & 0.054 & 0.513 & 0.558 & 0.055 & 0.399 & 0.138 & 0.442 \\
\hline 0.4 & 0.040 & 0.050 & 0.973 & 0.981 & 0.049 & 0.238 & 0.662 & 0.944 \\
\hline 0.6 & 0.040 & 0.048 & 1.000 & 1.000 & 0.038 & 0.099 & 0.975 & 0.998 \\
\hline 0.8 & 0.040 & 0.049 & 1.000 & 1.000 & 0.043 & 0.054 & 0.999 & 1.000 \\
\hline & \multicolumn{8}{|c|}{ C) $\mathrm{M} 1: \mathrm{W}=5$ nearest neighbors ; $\mathrm{M} 2: \mathrm{W}=$ Inverse square distance } \\
\hline 0.2 & 0.049 & 0.019 & 0.538 & 0.565 & 0.050 & 0.202 & 0.135 & 0.406 \\
\hline 0.4 & 0.049 & 0.019 & 0.972 & 0.983 & 0.038 & 0.263 & 0.698 & 0.937 \\
\hline 0.6 & 0.048 & 0.026 & 1.000 & 1.000 & 0.044 & 0.358 & 0.985 & 0.999 \\
\hline 0.8 & 0.052 & 0.037 & 1.000 & 1.000 & 0.042 & 0.281 & 0.999 & 1.000 \\
\hline & \multicolumn{8}{|c|}{ D) $\mathrm{M} 1: \mathrm{W}=20$ nearest neighbors ; $\mathrm{M} 2: \mathrm{W}=5$ nearest neighbors } \\
\hline 0.2 & 0.054 & 0.074 & 0.225 & 0.251 & 0.062 & 0.341 & 0.024 & 0.295 \\
\hline 0.4 & 0.049 & 0.068 & 0.676 & 0.697 & 0.046 & 0.316 & 0.058 & 0.394 \\
\hline 0.6 & 0.046 & 0.069 & 0.940 & 0.943 & 0.040 & 0.366 & 0.333 & 0.678 \\
\hline 0.8 & 0.045 & 0.066 & 0.997 & 0.997 & 0.047 & 0.420 & 0.777 & 0.934 \\
\hline & \multicolumn{8}{|c|}{ E) M1: $\mathrm{W}=20$ nearest neighbors ; M2: $\mathrm{W}=$ Exponential inverse distance } \\
\hline 0.2 & 0.039 & 0.061 & 0.281 & 0.291 & 0.072 & 0.419 & 0.023 & 0.319 \\
\hline 0.4 & 0.038 & 0.062 & 0.778 & 0.787 & 0.058 & 0.257 & 0.101 & 0.476 \\
\hline 0.6 & 0.036 & 0.055 & 0.976 & 0.977 & 0.032 & 0.102 & 0.502 & 0.837 \\
\hline 0.8 & 0.037 & 0.057 & 1.000 & 1.000 & 0.055 & 0.093 & 0.919 & 0.987 \\
\hline & \multicolumn{8}{|c|}{ F) $M 1: W=20$ nearest neighbors ; $M 2: W=$ Inverse square distance } \\
\hline 0.2 & 0.043 & 0.026 & 0.272 & 0.292 & 0.075 & 0.237 & 0.015 & 0.236 \\
\hline 0.4 & 0.043 & 0.032 & 0.743 & 0.757 & 0.045 & 0.150 & 0.14 & 0.426 \\
\hline 0.6 & 0.049 & 0.039 & 0.962 & 0.964 & 0.045 & 0.148 & 0.567 & 0.820 \\
\hline 0.8 & 0.044 & 0.039 & 0.999 & 1.000 & 0.043 & 0.130 & 0.948 & 0.988 \\
\hline & \multicolumn{8}{|c|}{ G) $\mathrm{M} 1: \mathrm{W}=$ Exponential inverse distance ; $\mathrm{M} 2: \mathrm{W}=5$ nearest neighbors } \\
\hline 0.2 & 0.045 & 0.062 & 0.119 & 0.134 & 0.078 & 0.355 & 0.020 & 0.285 \\
\hline 0.4 & 0.044 & 0.061 & 0.361 & 0.401 & 0.060 & 0.344 & 0.027 & 0.172 \\
\hline 0.6 & 0.044 & 0.057 & 0.806 & 0.857 & 0.059 & 0.289 & 0.428 & 0.618 \\
\hline 0.8 & 0.049 & 0.061 & 0.999 & 1.000 & 0.050 & 0.369 & 0.968 & 0.985 \\
\hline & \multicolumn{8}{|c|}{ H) $\mathrm{M} 1: \mathrm{W}=$ Exponential inverse distance ; $\mathrm{M} 2: \mathrm{W}=20$ nearest neighbors } \\
\hline 0.2 & 0.038 & 0.049 & 0.114 & 0.141 & 0.074 & 0.428 & 0.020 & 0.282 \\
\hline 0.4 & 0.041 & 0.046 & 0.340 & 0.402 & 0.056 & 0.356 & 0.022 & 0.152 \\
\hline 0.6 & 0.040 & 0.048 & 0.804 & 0.852 & 0.042 & 0.327 & 0.410 & 0.601 \\
\hline 0.8 & 0.044 & 0.053 & 0.999 & 1.000 & 0.117 & 0.633 & 0.971 & 0.987 \\
\hline
\end{tabular}


Table 3: Comparison of $J$ test performance for the 2 predictors, $n=254$

\begin{tabular}{|c|c|c|c|c|c|c|c|c|}
\hline & \multicolumn{4}{|c|}{ First Predictor } & \multicolumn{4}{|c|}{ Second Predictor } \\
\hline \multirow{3}{*}{$\lambda$} & \multicolumn{2}{|c|}{ Rej. Rate $J$ test M1 } & \multicolumn{2}{|c|}{ Rej. Rate $J$ test M2 } & \multicolumn{2}{|c|}{ Rej. Rate $J$ test M1 } & \multirow{2}{*}{\multicolumn{2}{|c|}{$\begin{array}{l}\text { Rej. Rate } J \text { test M2 } \\
\text { Boot. Asvmp }\end{array}$}} \\
\hline & Boot. & Asymp. & Boot. & Asymp. & Boot. & Asymp. & Boot. & \\
\hline & \multicolumn{8}{|c|}{ A) M1: $\mathrm{W}=5$ nearest neighbors ; $\mathrm{M} 2: \mathrm{W}=20$ nearest neighbors } \\
\hline 0.2 & 0.046 & 0.045 & 0.969 & 0.974 & 0.056 & 0.231 & 0.321 & 0.665 \\
\hline 0.4 & 0.048 & 0.045 & 1.000 & 1.000 & 0.039 & 0.173 & 0.939 & 1.000 \\
\hline 0.6 & 0.045 & 0.044 & 0.998 & 0.998 & 0.036 & 0.237 & 0.998 & 1.000 \\
\hline \multirow[t]{2}{*}{0.8} & 0.048 & 0.066 & 0.999 & 0.999 & 0.055 & 0.371 & 1.000 & 1.000 \\
\hline & \multicolumn{8}{|c|}{ B) M1: $W=5$ nearest neighbors ; M2: $W=$ Exponential inverse distance } \\
\hline 0.2 & 0.040 & 0.049 & 0.984 & 0.986 & 0.059 & 0.118 & 0.498 & 0.745 \\
\hline 0.4 & 0.041 & 0.049 & 1.000 & 1.000 & 0.047 & 0.069 & 0.995 & 1.000 \\
\hline 0.6 & 0.042 & 0.051 & 1.000 & 1.000 & 0.045 & 0.055 & 1.000 & 1.000 \\
\hline 0.8 & 0.046 & 0.055 & 1.000 & 1.000 & 0.049 & 0.057 & 1.000 & 1.000 \\
\hline & \multicolumn{8}{|c|}{ C) $\mathrm{M} 1: \mathrm{W}=5$ nearest neighbors ; $\mathrm{M} 2: \mathrm{W}=$ Inverse square distance } \\
\hline 0.2 & 0.046 & 0.053 & 0.99 & 0.99 & 0.038 & 0.105 & 0.525 & 0.741 \\
\hline 0.4 & 0.048 & 0.050 & 1.000 & 1.000 & 0.033 & 0.165 & 0.999 & 1.000 \\
\hline 0.6 & 0.047 & 0.054 & 1.000 & 1.000 & 0.039 & 0.22 & 1.000 & 1.000 \\
\hline 0.8 & 0.048 & 0.054 & 1.000 & 1.000 & 0.047 & 0.168 & 1.000 & 1.000 \\
\hline & \multicolumn{8}{|c|}{ D) $\mathrm{M} 1: \mathrm{W}=20$ nearest neighbors ; $\mathrm{M} 2: \mathrm{W}=5$ nearest neighbors } \\
\hline 0.2 & 0.065 & 0.071 & 0.552 & 0.569 & 0.062 & 0.283 & 0.050 & 0.258 \\
\hline 0.4 & 0.061 & 0.072 & 0.975 & 0.3 & 0.026 & 0.294 & 0. & 0.582 \\
\hline 0.6 & 0.056 & 0.068 & 0.999 & 1.0 & 0.027 & 0.494 & 0.8 & 0.928 \\
\hline 0.8 & 0.056 & 0.080 & 0.999 & 0.999 & 0.034 & 0.561 & 0.986 & 0.997 \\
\hline & \multicolumn{8}{|c|}{ E) $\mathrm{M} 1: \mathrm{W}=20$ nearest neighbors ; $\mathrm{M} 2: \mathrm{W}=$ Exponential inverse distance } \\
\hline 0.2 & 0.050 & 0.056 & 0.670 & 0.683 & 0.059 & 0.119 & 0.064 & 0.288 \\
\hline 0.4 & 0.050 & 0.055 & 0.988 & 0.990 & 0.051 & 0.076 & 0.421 & 0.711 \\
\hline 0.6 & 0.046 & 0.064 & 1.000 & 1.000 & 0.046 & 0.068 & 0.873 & 0.976 \\
\hline 0.8 & 0.046 & 0.062 & 0.999 & 0.999 & 0.046 & 0.071 & 0.997 & 1.000 \\
\hline & \multicolumn{8}{|c|}{ F) M1: $\mathrm{W}=20$ nearest neighbors ; $\mathrm{M} 2: \mathrm{W}=$ Inverse square distance } \\
\hline 0.2 & 0.044 & 0.057 & 0.693 & 0.702 & 0.067 & 0.127 & 0.093 & 0.236 \\
\hline 0.4 & 0.045 & 0.053 & 0.995 & 0.995 & 0.039 & 0.111 & 0.514 & 0.742 \\
\hline 0.6 & 0.045 & 0.054 & 1.000 & 1.000 & 0.042 & 0.161 & 0.934 & 0.985 \\
\hline 0.8 & 0.050 & 0.054 & 1.000 & 1.000 & 0.039 & 0.141 & 0.999 & 1.000 \\
\hline & \multicolumn{8}{|c|}{ G) M1: $\mathrm{W}=$ Exponential inverse distance ; $\mathrm{M} 2: \mathrm{W}=5$ nearest neighbors } \\
\hline 0.2 & 0.061 & 0.066 & 0.441 & 0.462 & 0.083 & 0.295 & 0.140 & 0.215 \\
\hline 0.4 & 0.062 & 0.067 & 0.990 & 0.992 & 0.046 & 0.248 & 0.925 & 0.947 \\
\hline 0.6 & 0.065 & 0.071 & 1.000 & 1.000 & 0.057 & 0.479 & 1.000 & 1.000 \\
\hline 0.8 & 0.065 & 0.062 & 1.000 & 1.000 & 0.123 & 0.527 & 1.000 & 1.000 \\
\hline & \multicolumn{8}{|c|}{ H) $\mathrm{M} 1: \mathrm{W}=$ Exponential inverse distance ; $\mathrm{M} 2: \mathrm{W}=20$ nearest neighbors } \\
\hline 0.2 & 0.052 & 0.053 & 0.453 & 0.475 & 0.076 & 0.276 & 0.135 & 0.217 \\
\hline 0.4 & 0.055 & 0.054 & 0.992 & 0.993 & 0.041 & 0.278 & 0.916 & 0.948 \\
\hline 0.6 & 0.051 & 0.057 & 1.000 & 1.000 & 0.108 & 0.698 & 1.000 & 1.000 \\
\hline 0.8 & 0.061 & 0.064 & 1.000 & 1.000 & 0.032 & 0.064 & 1.000 & 1.000 \\
\hline
\end{tabular}


from the first or the second predictor for each of the two sample sizes: 100 and 254. In these Monte Carlo, we consider two competing SAR models which only differ by the interaction matrix. The first model (M1) is the true model while the second model (M2) is based on a wrong interaction matrix. Hence, the rejection rate of the $J$ statistic associated to M1 assesses the size of the test while the rejection rate of the $J$ test of M2 is a measure of its power. In the simulations we also compare the performance of the test based on an asymptotic distribution $\left(\chi_{1}^{2}\right)$ with the performance based on bootstrap, where 399 replications were used.

We first analyze the results of Table 2, associated to $n=100$. For both predictors, the size of the test based on bootstrap is always around the theoretical value of $5 \%$ which shows the good performance of the bootstrap approach. However, when considering asymptotic distribution, size distortion appears, especially for the second predictor, with rejection rates reaching $42 \%$, instead of the theoretical 5\%. For the bootstrap inference, we thus cannot base our predictor selection on size considerations. Looking at rejection rates of the $J$ test associated to M2, we observe important difference between the 2 predictors, no matter the interaction matrices used in the 2 models. The rejection rate for the first predictor is much higher than for the second one, implying a higher power. This is especially true for low to moderate values of $\lambda$ but differences are also noticeable for higher values of $\lambda$. We also note a lower power for the second predictor when inference is based on bootstrap rather than on asymptotic distribution while it is not the case for the first predictor.

The same patterns are observed considering the bigger sample size, $n=254$, as shown in Table 3. Power differences between the 2 predictors are still present, even though less important. This result may be explained by the increase in the number of observations. Nevertheless, we also observe cases where the second predictor performs poorly compared to the first predictor. For instance, in case D), when $\lambda=0.4$ the bootstrapped power for Predictor 2 is equal to 0.331 while for Predictor 1, we observe a bootstrapped power of 0.975 .

Hence, mainly for power reasons, we propose to rely on the first predictor (based on the reduced form of the alternative model) to construct the $J$ test. 


\section{The $M J$-test}

The $J$ test presented above is a procedure for testing a null model against non-nested alternatives. It is generally known that tests of non-nested models may cause to a problem of model selection when inverting the null and alternative hypotheses do not give clear-cut results. To overcome this drawback, Hagemann (2012) suggests a simple test, the $M J$ (minimum $J$ ) statistic which allows to always select a model between competing alternatives. The $M J$ statistic consists in selecting the model with the smallest associated $J$ statistic value. In this paper, we extend the use of the $M J$ test procedure to a spatial framework and more precisely to the selection of the interaction matrix in spatial autoregressive models.

Assume that one wishes to find the most appropriate interaction matrix among a set of $M$ spatial autoregressive models.

$$
Y_{n}=X_{n} \beta_{m}+\lambda_{m} W_{m n} Y_{n}+\varepsilon_{m n}, \quad m \in \mathcal{M}=\{1, \ldots, M\}
$$

with $\varepsilon_{m n}$, the $n \times 1$ vector of independent error terms with $\varepsilon_{i, m n}$ characterized by a zero mean and a variance $\sigma_{i, m n}^{2}, i=1, \cdots, n$ and $\theta_{m}=\left(\lambda_{m}, \beta_{m}^{\prime}\right)^{\prime}$ is the vector of regression parameters to be estimated for $m=1, \ldots, M$. The $M J$ test procedure is the following:

Step 1: For each $m \in \mathcal{M}$, compute the $J$ test of the null hypothesis $H_{0}$ corresponding to model $m$ against $M-1$ alternatives non-nested hypotheses.

For this, it is necessary to estimate the augmented model:

$$
Y_{n}=X_{m n} \beta_{m}+\lambda_{m} W_{m n} Y_{n}+\sum_{l \in \mathcal{M} \backslash\{m\}} \delta_{l} \widehat{y}_{n}^{l}+\varepsilon_{m n}
$$

Construct then $\widehat{J}_{m, n}$, the $J$-test associated to model $m$, as a test of joint significance of $\delta_{l}, l \in \mathcal{M} \backslash\{m\}$. The augmented model can be estimated by the two-step optimal RGMM estimation method discussed above. 
Step 2: Let $\mathcal{J}_{n}=\left\{\widehat{J}_{m, n}: m \in \mathcal{M}\right\}$ and define the least $J$ statistic: $M J_{n}=\min \mathcal{J}_{n}$. This step solves the decision problem inherent to the $J$ test since the preferred model in the set of the $M$ considered specifications will be the one with the smallest value of $\widehat{J}_{m, n}, m=1, \cdots M .^{13}$

\section{Application to the generalized Schumpeterian growth model}

The purpose of this section is to apply our testing procedure to the multi-country Schumpeterian growth model with worldwide interactions, proposed by Ertur \& Koch (2011). These authors propose an integrated theoretical and methodological framework characterized by technological interactions to explain growth processes from a Schumpeterian perspective. Their generalized Schumpeterian multi-country growth model, extending the one elaborated by Howitt (2000), explicitly takes into account global technological interdependence implied by R\&D spillovers. Moreover they show that a multi-country Solow growth model with technological interdependence similar to that proposed by Ertur \& Koch (2007) is actually nested in the generalized model leading to a simple test. Therefore, their generalized model can be interpreted as a Schumpeterian extension of the Solow growth model since in addition to factor accumulation, they show that innovation caused by $R \& D$ investment plays a major role in explaining the growth process. The model includes both determinants, with technological diffusion occurring concretely between pairs of countries, human capital reflecting absorptive capacity along the lines of Nelson \& Phelps (1966), and physical capital playing the usual role. More specifically, they show that when the R\&D expenditures have no effect on the growth rate of technology, the multi-country Schumpeterian growth model reduces to the multi-country Solow growth model. ${ }^{14}$

Their empirical results show that the multi-country pure Solow growth model is rejected in favor

\footnotetext{
${ }^{13}$ Hagemann (2012) also proposes to test whether the correct model is part of the considered ones by performing statistical inference on the $M J_{n}$. However, this theoretical consideration can only be assessed in Monte Carlo simulations where the DGP is fixed. The interested reader may consult their Monte Carlo results to obtain further details on the behavior of this test.

${ }^{14}$ The interested reader can refer to Ertur \& Koch (2011) for the full development of the multi-country Schumpeterian growth model.
} 
of the multi-country Schumpeterian growth model, once both models are integrated in a unified theoretical and methodological framework characterized by technological interdependence. They finally estimate the TFP equation implied by their multi-country Schumpeterian growth model as well as the international R\&D spillovers implied by technological interdependence using two different interaction matrices based on geographical distance and trade flows. The main result they underline is the fact that their model allows to have multiple local technological leaders: besides USA, Germany and Japan are also playing that role in their respective area of influence.

\subsection{The econometric specification}

Due to space limitation, we will focus here more specifically on the TFP equation implied by the multi-country growth model developed by Ertur \& Koch (2011, eq. 59, p.234):

$$
\ln T F P_{i}=\beta_{0}+\beta_{1} \ln \frac{s_{K, i}}{n_{i}+0.05}+\beta_{2} \ln s_{A, i}+\beta_{3} \ln n_{i}+\gamma H_{i} \sum_{j \neq i}^{n} v_{i j} \ln T F P_{j}+\varepsilon_{i}
$$

where $\ln T F P_{i}$ is the logarithm of Total Factor Productivity of country $i$ at steady state (taking one third as the capital's share in income); $\beta_{1}$ is the coefficients associated with the logarithm of the investment rate divided by the effective depreciation rate $\ln \frac{s_{K, i}}{n_{i}+0.05}, \beta_{2}$ is the coefficient associated with the logarithm of the investment rate in the research sector $\ln s_{A, i}$ and $\beta_{3}$ is the coefficient associated to the logarithm of the working-age population growth rate $n_{i} . H_{i}$ is the stock of human capital, which is designed to measure the capacity of absorption of new technology for country $i$. Finally $\gamma$ is the autoregressive interaction parameter. In matrix form, the model is written as follows, in cross-section:

$$
Y=\beta_{0} \iota+\beta_{1} S_{K}+\beta_{2} S_{A}+\beta_{3} N+\gamma W y+\varepsilon
$$

where $Y$ is the $(n \times 1)$ vector of the logarithms of TFP; $\iota$ is the unit vector, $S_{K}$ is the vector

of the logarithms of the investment rates in physical capital divided by the effective depreciation 
rates, $S_{A}$ is the vector of the logarithms of expenditures in the research sector and $N$ is the vector of the logarithms of working-age population growth rates. $W$ is the interaction matrix modeling technological interactions as a function of the new technology absorption capacity of the receiving country and some ad hoc measure of similarity between countries with general term $w_{i j}=H_{i} v_{i j}$. We will consider in the application different definitions of similarity $v_{i j}$ and select the most relevant one given the information contained in the sample.

\subsection{Data and interaction matrices}

For the sake of comparability we use the same database as Ertur \& Koch (2011). The data are extracted from the Heston et al. (2006) Penn World Tables (PWT version 6.2), containing information on real income, investment and population for a large number of countries. Data on R\&D expenditures come from the World Investment Report (2005) of the United Nations Conference on Trade and Development (UNCTD). The sample contains 58 countries and includes 21 OECD countries over the period 1990-2003. ${ }^{15}$ The explanatory variables are constructed as follows. To measure $n_{i}$, for $i=1, \ldots, n$, as the average growth of the working-age population (ages 15 to 64$)$, it is necessary to compute the number of workers as: $R G D P C H \times P O P / R G D P W$, where $R G D P C H$ is real GDP per capita computed by the chain method, $R G D P W$ is real-chain GDP per worker, and $P O P$ is the total population. The saving rate $s_{K, i}$, for $i=1, \ldots, n$, is measured as the average share of gross investment in GDP over the period as in Mankiw et al. (1992). The variable $s_{A, i}$, is measured as the average share gross domestic expenditure on R\&D (GERD) relative to GDP over the 1991-2001 period. As suggested by Mankiw et al. (1992) among others, we use $g_{w}+\delta=0.05$. Finally, the human capital stock is measured using the Mincerian equation, as proposed by Hall \& Jones (1999) or Caselli (2005), from the data of the database developed by Cohen \& Soto (2007). ${ }^{16}$ The dependent variable is defined in Ertur \& Koch (p.234,

\footnotetext{
${ }^{15}$ Due to missing data for the computation of the linguistic interaction matrix, we exclude South Korea from the sample as Korean is generally admitted to be a language isolate.

${ }^{16}$ This database is available at: http://www.parisschoolofeconomics.eu/fr/cohen-daniel/base-de-donnees-internationale-education/.
} 
2011) and computed as $\ln T F P_{i}=\ln y_{i}-0.5 \ln \frac{s_{K, i}}{n_{i}+0.05}$ where $y_{i}$ is the real income per worker in 2003. Table 4 provides some descriptive statistics over the variables used in our specification.

Table 4: Descriptive statistics

\begin{tabular}{c|ccccc} 
& Min & Max & Mean & Median & St. err. \\
\hline $\ln T F P$ & 3.2444 & 4.5469 & 4.1123 & 4.1789 & 0.3223 \\
$H_{i}$ & 1.0287 & 3.4632 & 2.3597 & 2.2724 & 0.6172 \\
$\ln s_{A}$ & -3.6815 & -1.3694 & -2.5357 & -2.6789 & 0.6779 \\
$\ln n$ & -1.5016 & -1.3463 & -1.4333 & -1.4397 & 0.0427 \\
$\ln \frac{s_{K}}{n+0.05}$ & -0.1363 & 0.3867 & 0.2169 & 0.2284 & 0.1229 \\
\hline
\end{tabular}

The first interaction matrix $W 1$ we consider is based on genealogical or "genetic" distance following Spolaore \& Wacziarg $(2009,2013) .{ }^{17}$ This notion of distance corresponds to the time elapsed since two populations shared a common ancestor. In other words, the genetic distance is a measure of relatedness between populations over time. It can be interpreted as a general metric for average differences in characteristics transmitted across generations. Moreover they argue that: "...by its very definition, genetic distance is an excellent summary statistic capturing divergence in the whole set of implicit beliefs, customs, habits, biases, conventions, etc. that are transmitted across generations - biologically and/or culturally - with high persistence." (Spolaore \& Wacziarg 2009, p.471). The general idea is that more closely related societies are more likely to learn from each other and adopt each other's innovations. Spolaore \& Wacziarg $(2009,2013)$ show that this general genealogical measure between populations may then explain income differences today. Their interpretation is that the genetic distance captures the barriers to the diffusion of development.

Several measures of genetic distance have been proposed in the literature related to population genetics. The most popular are FST distance or "co-ancestor coefficient" (Wright 1965) and Nei's distance (Nei 1973). These two measures have slightly different theoretical properties but their correlation is very strong. Thus, the choice of one these should not affect the results. The basic unit of these measures is the allele, which is a form taken by a gene. Differences in allele frequencies

\footnotetext{
${ }^{17}$ The term genetic distance comes from the literature related to population genetics and is also used in linguistics to refer to a measure of relatedness.
} 
hence form the basis of summary measures of calculating distance between populations. The genetic distance matrix $W 1$ used here is based on the differentiation coefficient $G_{S T}$ of Nei which corresponds to the probability that two randomly selected variants in a population are different. Nei (1973) propose indexes based on allele frequencies that describe the level and organization of diversity within populations. These indexes portray the total diversity $\left(h_{T}\right)$, the average intrapopulation diversity $\left(h_{S}\right)$ or differentiation between populations $\left(G_{S T}\right)$. $G_{S T}$ takes a value equal to zero if and only if the distributions of alleles are identical between the two populations, whereas it is positive when the distributions of alleles are different. A greater distance measure $G_{S T}^{W}$ reflects a longer separation between populations. However, like many countries, such as United States and Australia, are composed of sub-populations that are genealogically distant, it is preferable to use a weighted measure of genealogical distance $G_{S T}$. Thus, the interaction matrix $W 1$ is based on a decreasing function of the weighted genealogical distance $G_{S T}^{W}$ between countries whose functional form is the negative exponential of the distance. The general term of this matrix $W 1$ is defined as $w 1_{i j}=H_{i} v 1_{i j}$ with:

$$
v 1_{i j}= \begin{cases}0 & \text { if } i=j \\ e^{-g_{i j}} / \sum_{j \neq i} e^{-g_{i j}} & \text { otherwise }\end{cases}
$$

where $g_{i j}$ represents the weighted genetic distance $G_{S T}^{W}$ between countries $i$ and $j$ and $H_{i}$ is the human capital stock of the receiving country $i$.

The second interaction matrix $W 2$ we consider is based on a linguistic proximity concept following Melitz \& Toubal (2014). They summarize the evidence about the linguistic influences in an aggregate index, named Common Language index (CL), resting strictly on exogenous linguistic factors. This summary index (CL) is obtained using three indexes: Common Official Language (COL), Common Native Language (CNL) and Language Proximity (LP). ${ }^{18}$ The Common Language index (CL) ranges between 0 and 1. More precisely, CL takes a value equal to zero if the degree

\footnotetext{
${ }^{18}$ Data on Common Language are available at http://www.cepii.fr/cepii/en/bdd_modele/presentation.asp?id=19.
} 
of linguistic proximity between two countries is null, whereas CL tends to 1 when the linguistic proximity between these two countries is high. The general term of this matrix $W 2$ is defined as $w 2_{i j}=H_{i} v 2_{i j}$ with:

$$
v 2_{i j}= \begin{cases}0 & \text { if } \quad i=j \\ C L_{i j} / \sum_{j \neq i} C L_{i j} & \text { otherwise }\end{cases}
$$

where $C L_{i j}$ represents the Common Language Index (CL) between countries $i$ and $j$ and $H_{i}$ is the human capital stock of the receiving country $i$.

The last considered interaction matrix $W 3$ is based on trade flows. Indeed, trade flows may proxy multi-country technological interactions. ${ }^{19}$ The general term of this matrix is defined as $w 3_{i j}=H_{i} v 3_{i j}$ where:

$$
v 3_{i j}= \begin{cases}0 & \text { if } i=j \\ m_{i j} / \sum_{j \neq i} m_{i j} & \text { otherwise }\end{cases}
$$

where $m_{i j}$ is defined as the average imports of country $i$ coming from country $j$ computed over the 1990-2000 period to prevent endogeneity problems that might arise, using the bilateral trade flows database from CEPII, and $H_{i}$ is the human capital stock of the receiving country $i$. Ertur \& Koch (2011) use a different international trade database and define a block triangular interaction matrix assuming that the North club (OECD countries) diffuses its knowledge to the South club (the rest of the countries of their sample), but the opposite does not occur (see Appendix 2, p.250, Ertur \& Koch (2011)). Here we relax this assumption and further allow the South club to diffuse its knowledge to the North club. Hence this interaction matrix is full.

\footnotetext{
${ }^{19}$ The choice of this matrix is justified by studies of Grossman \& Helpman (1991), Coe \& Helpman (1995) and Coe et al. (1997) which show that international trade may be seen as a major diffusion vector of technological progress.
} 


\subsection{Econometric results}

The TFP equation (29) implied by the multi-country Schumpeterian growth model and the international R\&D spillovers implied by technological interdependence, is estimated by the RGMM procedure described in section 2 using the three interaction matrices based on genealogical distance $(W 1)$, linguistic distance $(W 2)$, and trade flows $(W 3)$. Each matrix has been normalized by the minimum between the maximal values of the row sums and column sums, as suggested in Kelejian \& Prucha (2010, Lemma 2, p.56). Estimation results are presented in Table 5. They are consistent with those obtained by Ertur \& Koch (2011) using different interaction matrices, underlying the robustness of the model. ${ }^{20}$ The coefficient associated with R\&D expenditures is significant whatever the interaction matrix considered. Its estimated value ranges from 0.170 to 0.184 . We also note that the spatial autocorrelation parameter is significant and has an estimated value ranging from 0.210 to 0.220 . Thus, the TFP of one country cannot be considered as independent from that of other countries. The coefficients of the investment rate divided by the effective depreciation rate and of the working-age population growth rate are non-significant as in Ertur \& Koch (2011, Table 2, p.242).

\subsubsection{Application of tests for non-nested spatial models}

In order to provide considerable help in the selection of the interaction matrix, we apply the $J$ tests to equation (29) and then use the $M J$ procedure to select the most adequate interaction matrix (amongst those considered). The results are presented in Table 6. We first observe that bootstrapped p-values are much higher than p-values based on asymptotic distribution $\left(\chi_{2}^{2}\right)$. This result is in line with what we found in the Monte Carlo experiments. Further, none of the three $J$ tests are significant, implying a decision problem with respect to the selection of the interaction matrix. Indeed, the (bootstrapped) p-values are all higher than 5\%. To overcome this decision

\footnotetext{
${ }^{20}$ Note that Ertur \& Koch (2011) estimate also a constrained model where they introduce some structural theoretical restrictions $\beta_{1}=\beta_{2}=\beta_{3}=\beta$ (p.241), which would take a lot of space to explain here. Therefore due to space limitation and for more simplicity, we only estimate here the unconstrained model. The interested reader could refer to this paper. Note also that the non-significance of $\beta_{1}$ and $\beta_{3}$ is a shared feature between the two papers.
} 
Table 5: Estimation Results

\begin{tabular}{c|ccc}
\hline \hline Estimation method & \multicolumn{3}{|c}{ SAR-RGMM } \\
Interaction matrix & $(W 1)$ & $(W 2)$ & $(W 3)$ \\
\hline \multirow{2}{*}{ Constant } & 4.3673 & 4.5860 & 4.4174 \\
& $(3.0078)$ & $(3.2079)$ & $(3.0574)$ \\
$\ln \left(s_{K} /(n+0.05)\right)$ & -0.0371 & -0.0187 & -0.0648 \\
& $(-0.0966)$ & $(-0.0480)$ & $(-0.1624)$ \\
$\ln s_{A}$ & 0.1702 & 0.1837 & 0.1785 \\
& $(2.2574)$ & $(2.4286)$ & $(2.3586)$ \\
$\ln n$ & 0.3083 & 0.4338 & 0.3204 \\
& $(0.3229)$ & $(0.4602)$ & $(0.3363)$ \\
$\gamma$ & 0.2199 & 0.2147 & 0.2101 \\
$n$ & $(3.1267)$ & $(3.1373)$ & $(3.0787)$ \\
\hline Pseudo- $R^{2}$ & 58 & 58 & 58 \\
\hline \hline
\end{tabular}

t-stats between brackets. Pseudo- $R 2$ is the squared correlation between predicted and actual values.

problem, we use the $M J$ test and select the model for which the associated $J$ statistic has the minimum value. This minimum value is obtained for the model with $W 3$, namely the interaction matrix based on a function of the capacity to absorb new technologies (measured by the stock of human capital of the receiving country) and on trade flows.

\begin{tabular}{cccc}
\multicolumn{4}{c}{ Table 6: $M J$ tests } \\
\hline$H_{0}:$ & $W 1$ & $W 2$ & $W 3$ \\
$H_{A}:$ & $W 2, W 3$ & $W 1, W 3$ & $W 1, W 2$ \\
\hline J-test & 3.538 & 3.225 & $\mathbf{2 . 8 3 5}$ \\
& $(0.354)$ & $(0.383)$ & $(0.512)$ \\
{$[0.171]$} & {$[0.199]$} & {$[0.242]$} \\
\hline Bootstrapped & p-values & between \\
brackets, using & 999 & replications and \\
asymptotically-based p-values between
\end{tabular}

On the basis of econometric results in Tables 5 and 6 and equation (14), we compute the impacts of home and foreign R\&D expenditures on the TFP of a given country using $W 3$, which is favored by the $M J$ test. We then obtain the $n \times n$ estimated matrix of elasticities, using the 
estimated coefficients of the econometric model. Results for OECD countries plus Brazil and China, displaying significant impacts are presented in Table $7 .^{21}$

Table 7 is divided in two parts: the upper part displays R\&D spillovers within the club of OECD countries (North-North R\&D spillovers) while the lower part shows R\&D spillovers from OECD countries to countries not belonging to this club (North-South R\&D spillovers). Results for China and Brazil are added in the last columns to give an insight into R\&D spillovers from non OECD emerging countries to countries belonging to the North club (South-North R\&D spillovers) and to the South club (South-South R\&D spillovers). The highlighted array elements on the main diagonal correspond to the direct elasticities,including feedback effects, that is the elasticity of the TFP of a given country with respect to its own R\&D expenditures.

We first note that the direct elasticities are all significant and only slightly higher than $\widehat{\beta}_{2}=$ 0.17855 when we take into account spatial autocorrelation, because of higher order feedback effects in the expansion (15). Even though these direct effects are heterogeneous by nature, in this application we do not observe much difference between countries, due to the fact that feedback effect are of small scale compared to the estimated value of $\hat{\beta}_{2}$. It is however interesting to note that those feedback effects are the highest for USA, Germany, Japan, Canada, France and United Kingdom (Figure 1). For OECD countries, they range from $0.1786 \%$ for Greece or Portugal to $0.1810 \%$ for USA, which benefits of the highest feedback effects, while the average direct impact including feedback effects is 0.1791 , i.e. on average, a $1 \%$ increase of their R\&D expenditures yields a $0.1791 \%$ increase of TFP. For countries not belonging to this club, on average, a $1 \%$ increase of their R\&D expenditures yields a $0.1786 \%$ increase in TFP, comparable to the direct impacts for Greece or Portugal.

Figure 2 presents results for significant indirect impacts, for the whole sample, which are our main concern here. Using Table 7, the flow of knowledge between countries $i$ and $j$ goes from the country in column $j$, the emitting country, to the country in row $i$, the receiving country. A

\footnotetext{
${ }^{21}$ Inference on impacts is based on simulating 1000 values of these impacts. As the estimators are shown to be normally distributed, for these simulations, we use a normal distribution centered on the estimated values of the parameters and with the covariance matrix of the estimated parameters.
} 


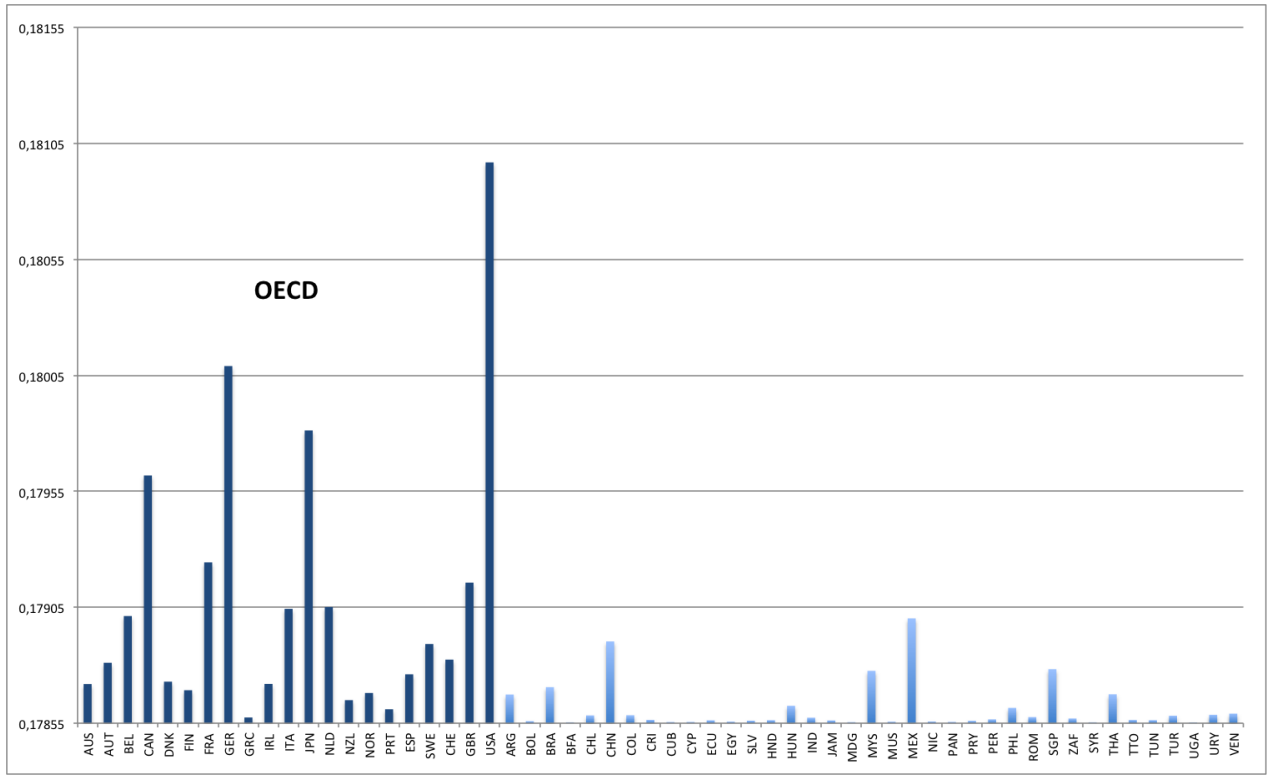

Figure 1: Direct impacts including heterogeneous feedback effects of a change of R\&D expenditures on the TFP of all countries using the trade based interaction matrix $(W 3)$.

network representation of those significant impacts is also proposed in Figure 3, in terms of weighted out-degrees based on the estimated value of significant indirect elasticities, i.e. the impact on the TFP of country $i$ of a $1 \%$ change of R\&D expenditures in country $j$, using the Fruchterman and Reingold force-directed algorithm (see Fruchterman \& Reingold 1991).

Second, with respect to indirect elasticities, i.e. the off-diagonal terms of the matrix in Table 7 , we note that the United States is the country, among OECD countries, which diffuses the most of its R\&D to other countries, followed first by Germany and Japan and second by France, UnitedKingdom and Italy (Figures 2 and 3). The indirect impact of a 1\% increase of R\&D expenditures in USA on the TFP of all other countries is $0.3051 \%$, whereas this impact is $0.2145 \%$ for Germany, 0.1718\% for Japan, $0.1173 \%$ for France, $0.1004 \%$ for Italy and $0.1002 \%$ for United Kingdom (see sums of the corresponding columns of Table 7 and Figure 2). Among the OECD group, countries which diffuse the least of their R\&D are Greece, New-Zealand and Portugal. Note also that the share of total intra OECD impact in the total impact ranges from $58 \%$ for USA to $99 \%$ for Portugal. For non-OECD countries, it is interesting to note that for China for instance the indirect impact of a $1 \%$ increase of R\&D expenditures on the TFP of all other countries is $0.045 \%$, an impact that 


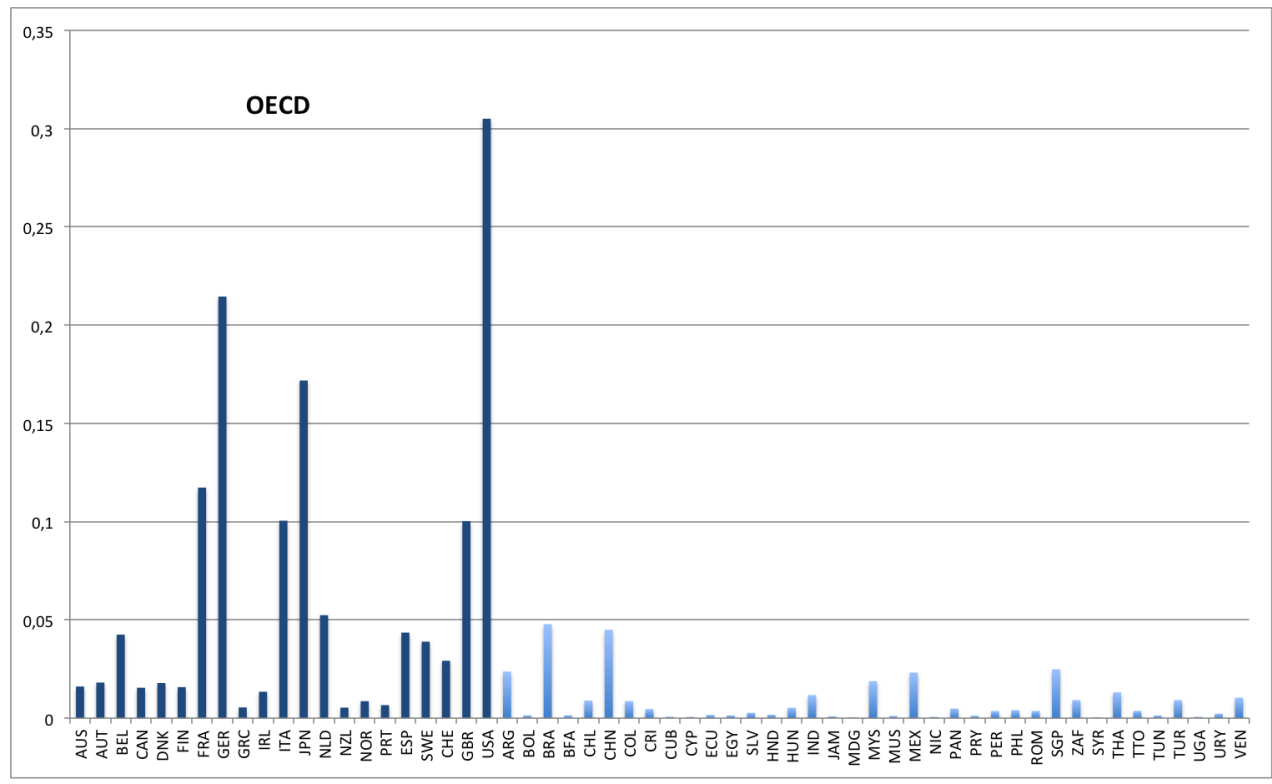

Figure 2: Indirect impacts of a change of R\&D expenditures on the TFP of all countries using the trade based interaction matrix $(W 3)$

is higher than impacts reported for most of the OECD countries. This is also the case for Brazil $(0.0478 \%)$.

In addition, a $1 \%$ increase in R\&D expenditures in USA yields a $0.0248 \%$ increase in Canadian TFP, whereas a $1 \%$ increase in R\&D expenditures in Canada only yields a $0.0075 \%$ increase in US TFP. This asymmetric effect is mainly due to the asymmetric nature of trade between USA and Canada. On average, for the period under study, only $19.82 \%$ of the total imports of USA come from Canada, whereas $67.27 \%$ of the total imports of Canada come from USA. Note also that the capacity of absorption of new technologies, as measured by human capital stocks, is slightly higher in USA (3.41) than in Canada (3.29). Figure 4 displays this capacity of absorption for all countries in the sample. Even though the value and significance of estimated coefficients in Table 5 are robust to the choice of interaction matrix, it is nevertheless highly important to select the right interaction matrix. To make our point, we show in Figures 5 and 6 the significant indirect effects obtained for the 2 other considered interaction matrices. We note that their patterns are completely different from each other, implying different policy recommendations. Further, the three local technological leaders identified using the interaction matrix based on trade do not appear anymore for interaction 


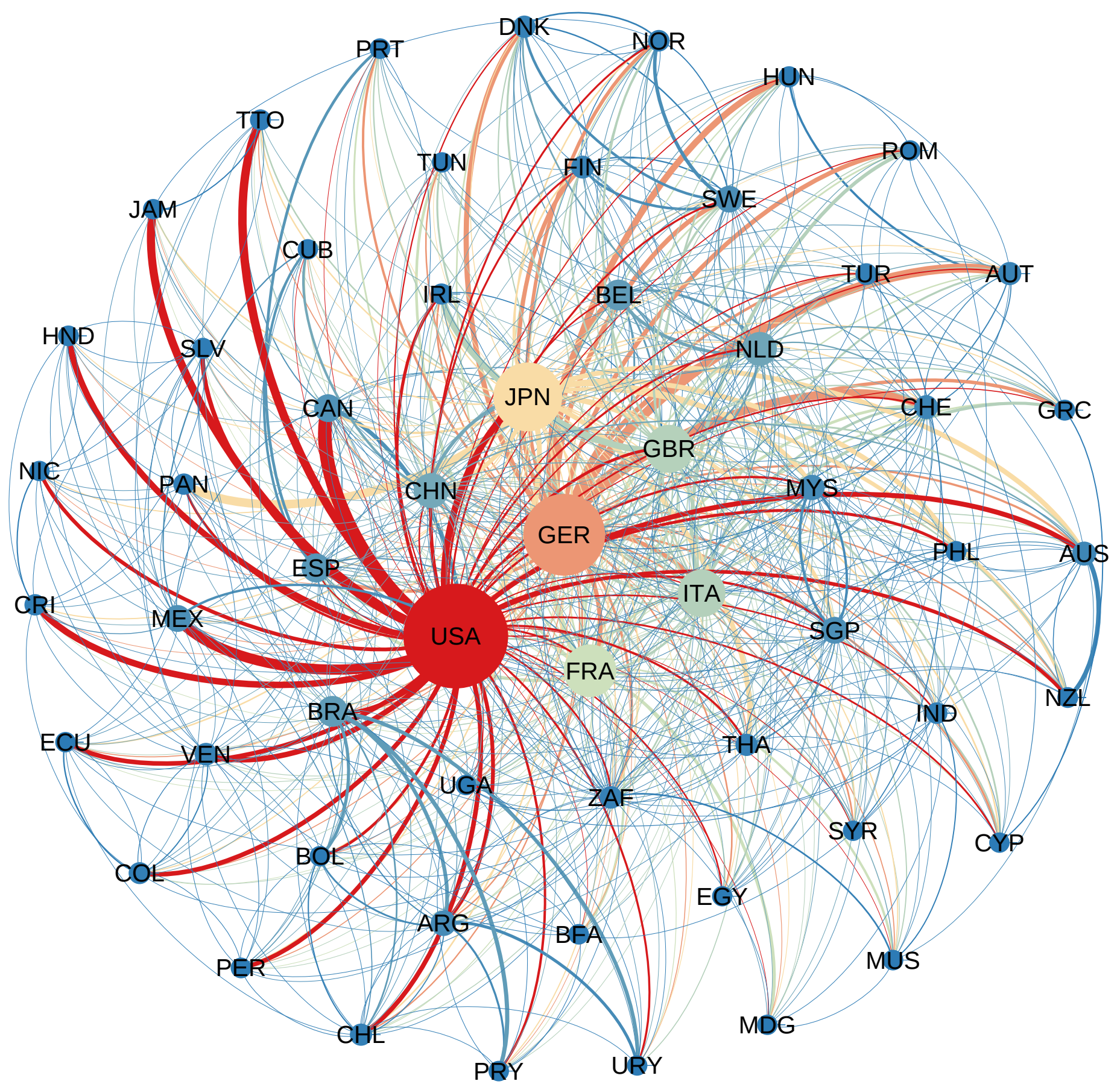

Figure 3: Network representation of significant indirect impacts (weighted out-degrees).

matrices based on linguistic or genealogical similarity.

It is also possible to interpret the results in terms of clubs. Inside the North club (OECD countries), the average indirect impact is 0.033 , i.e. on average, a $1 \%$ increase of the R\&D expenditures 


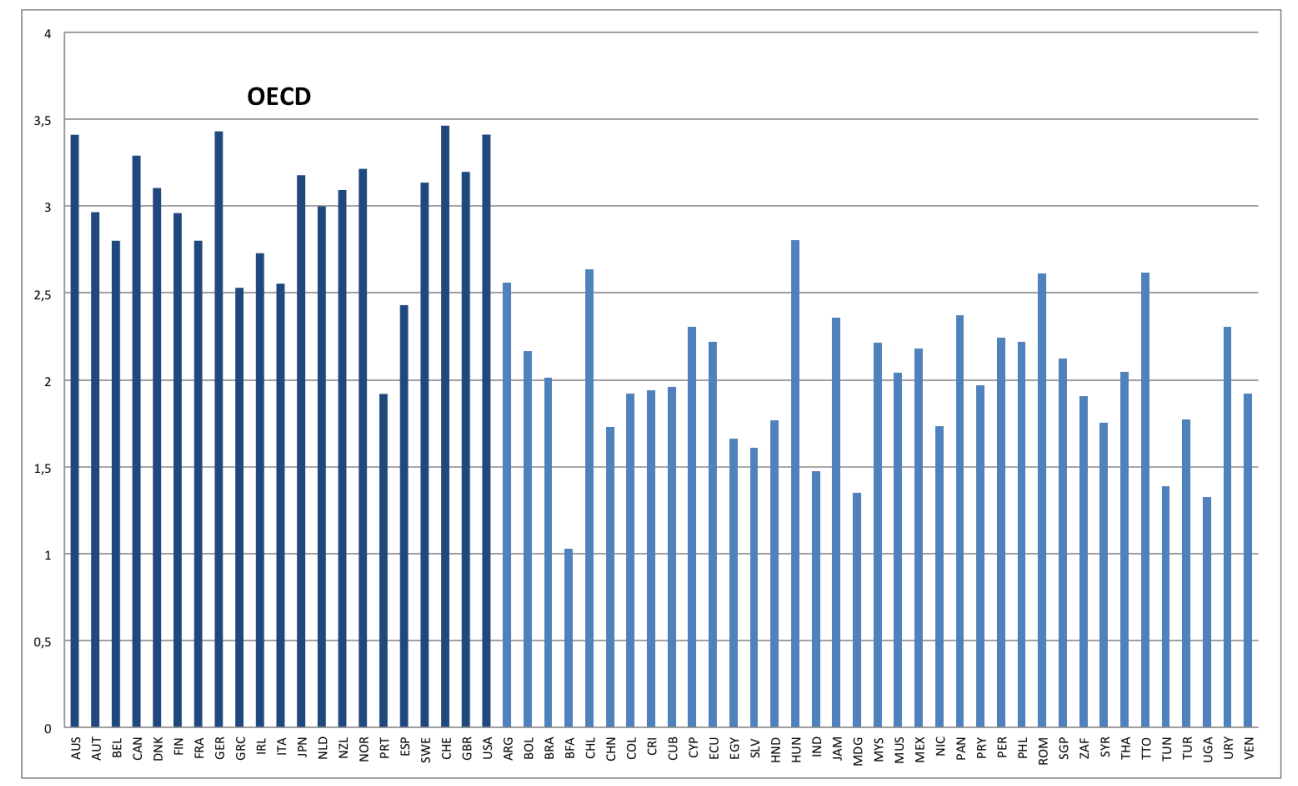

Figure 4: Human capital stock $\left(h_{i}\right)$ measured using the Mincerian equation, as proposed by Hall \& Jones (1999) or Caselli (2005), from the data of the database developed by Cohen \& Soto (2007).

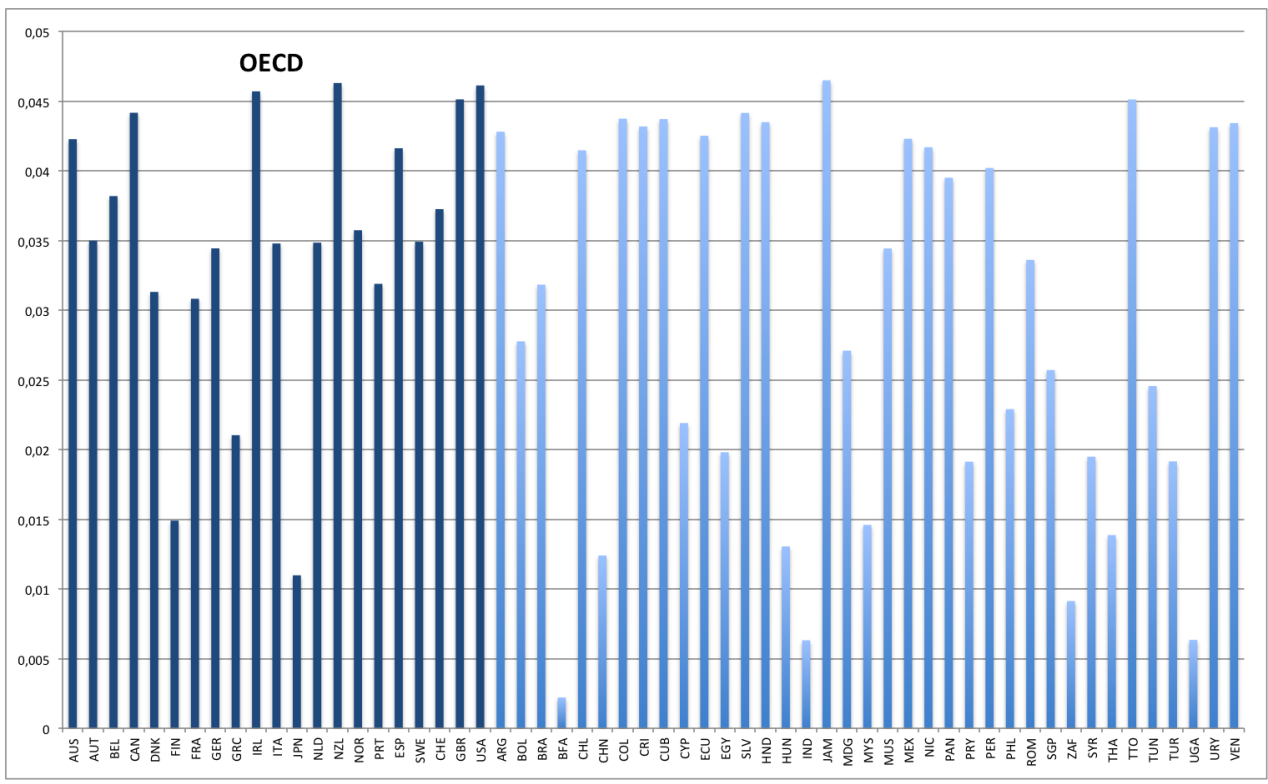

Figure 5: Indirect impacts of a change of $\mathrm{R} \& \mathrm{D}$ expenditures on the TFP of all countries using the linguistic distance based interaction matrix $(W 2)$. 


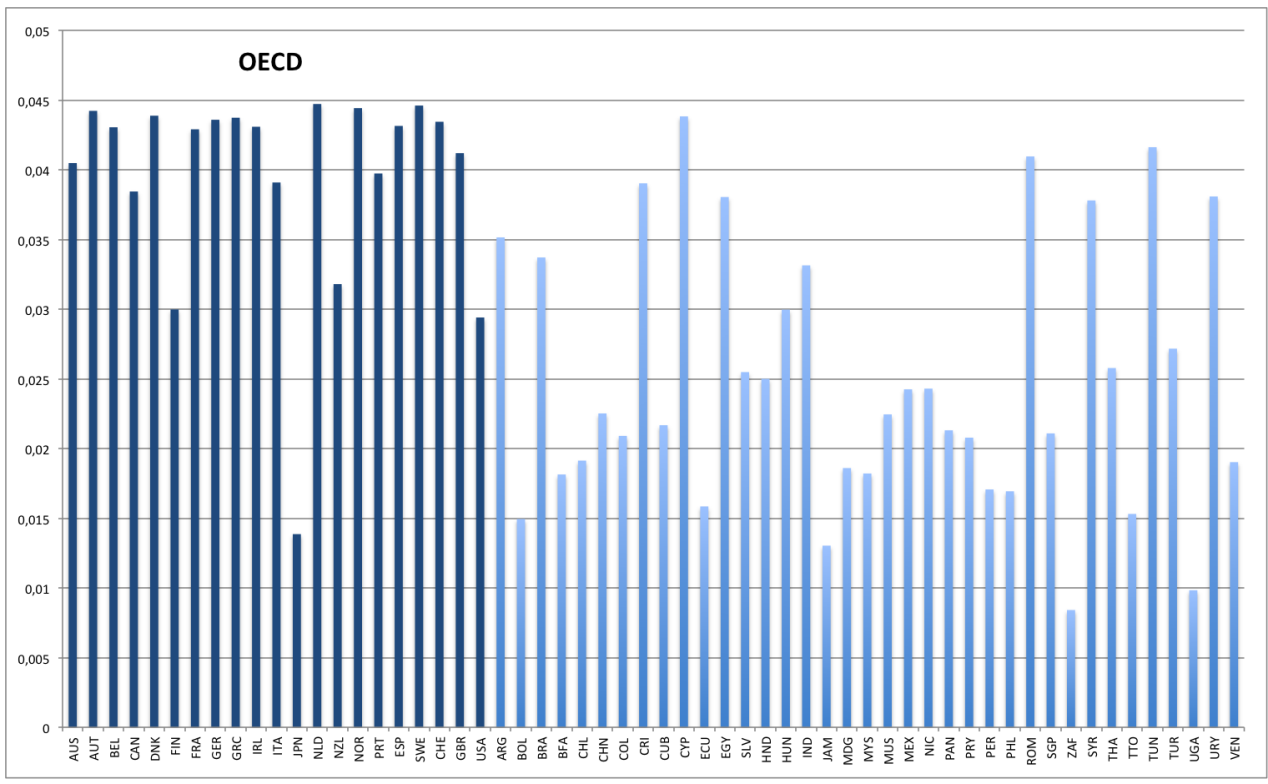

Figure 6: Indirect impacts of a change of R\&D expenditures on the TFP of all countries using the genealogical distance based interaction matrix $(W 1)$.

of a OECD country yields a $0.033 \%$ increase of the TFP of all other OECD countries. Inside the South club (non-OECD countries), on average, a 1\% increase of the R\&D expenditures yields a much lower $0.0061 \%$ increase of the TFP of the other countries. Not surprisingly, the North-South average indirect impact is on average $0.104 \%$, much higher than the South-North average indirect impact, which is $0.002 \%$ (see Table 7). Again, not surprisingly this North-South club heterogeneity comes from indirect effects, the direct effects being pretty similar across clubs.

Third, those results are essentially due to the weight of the United States in the international trade pattern. The United States R\&D diffusion impacts are higher for countries belonging to Central and South-America, such as Canada, Mexico, Trinidad and Tobago, Jamaica, Costa-Rica and Honduras for instance than for other countries belonging to the South Club. ${ }^{22}$ We also note the role played by the human capital stock in enhancing the absorption capacity of international R\&D diffusion since the impact on Canada (0.0248\%) is higher than the impact on Mexico $(0.0186 \%)$ although the latter has an higher import share from the United States. These results for United States show the influence of this country in the American continent, as also underlined by Coe et al.

\footnotetext{
${ }^{22}$ In our sample, Canada imports almost $67 \%$ from the United States, Mexico, 77\%; Trinidad and Tobago, $51 \%$; Jamaica, 54\%; Honduras, $56 \%$ and Costa-Rica, $53 \%$.
} 
Table 7: Average significant impacts for Clubs

\begin{tabular}{rll}
\hline \hline \multicolumn{1}{c}{ Club } & Mean & Median \\
\hline North - North & & \\
Direct impact & 0.1791 & 0.1788 \\
Indirect impact & 0.0331 & 0.0159 \\
Total impact & 0.2121 & 0.1948 \\
\hline North - South & & \\
Indirect impact & 0.1048 & 0.1048 \\
\hline South - South & & \\
Direct impact & 0.1786 & 0.1786 \\
Indirect impact & 0.0061 & 0.0024 \\
Total impact & 0.18543 & 0.17987 \\
\hline South - North & & \\
Indirect impact & 0.0021 & 0.0003 \\
\hline \hline
\end{tabular}

(1997). The elasticities from Japan to South East Asian countries are also higher than the elasticities from Japan to other countries belonging to the South club. The elasticities from Germany to other European countries are higher than the elasticity from Germany to other countries belonging to the south club. These results suggest that the United States is a natural technological leader for Central and Southern American countries, that Japan is the technological leader in South East Asia and that Germany is the technological leader in Europe.

Finally, using the network representation in Figure 7, obtained by using additional information on the coordinates of the country capitals for the localization of the nodes, we note that knowledge diffuses locally between European countries where indirect estimated elasticities are higher for larger emitting countries as Germany, France, United Kingdom or Italy than for smaller countries. confirming that Germany appears as the European technological leader. We also note that the elasticities between European and African countries are relatively high, showing the importance of European countries (essentially France and to some extend United Kingdom) as technological leaders for African countries (see Table 7). ${ }^{23}$

\footnotetext{
${ }^{23}$ In Figures 3 and 7, for the sake of readability, we omit of the network representations the links that were very close to $0(<0.0005)$.
} 


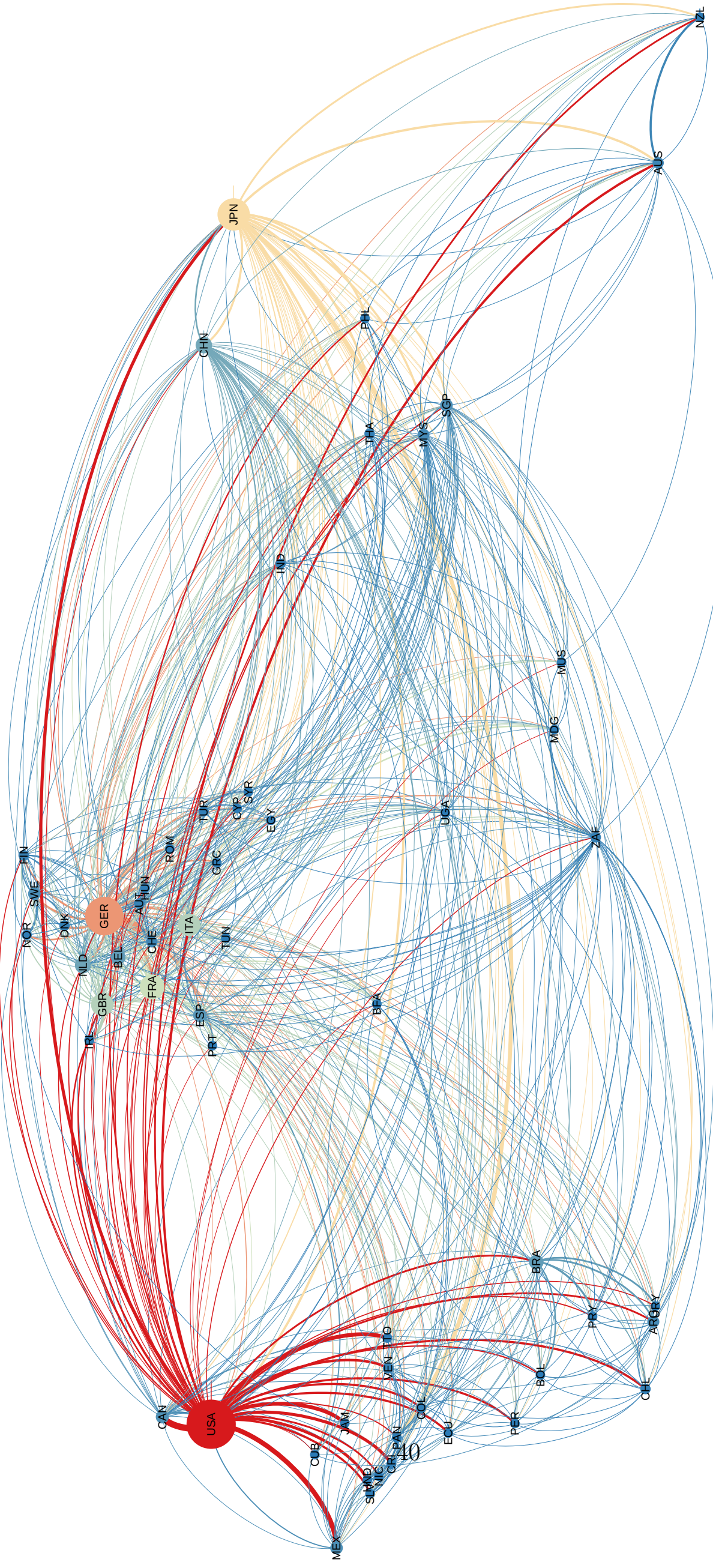

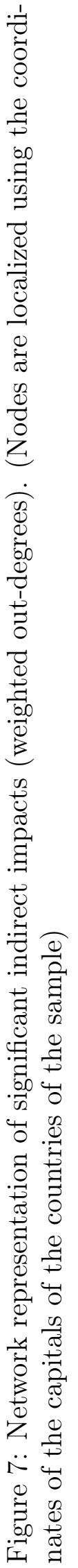




\section{Conclusions}

We propose a solution to the interaction matrix selection problem in spatial econometric models using the RGMM estimation method proposed by Lin \& Lee (2010), which consists in a new, robust against unknown heteroskedasticity, version of the $J$ test first proposed by Kelejian (2008) and modified by Kelejian \& Piras (2011). Moreover the common model selection problem that arises with non-nested hypotheses tests is overcome using the approach recently proposed by Hagemann (2012), called the $M J$ test.

We then apply this non-nested hypotheses testing procedure to the the multi-country Schumpeterian growth model proposed by Ertur \& Koch (2011) to discriminate between three different types of interaction matrices: genetic distance, linguistic proximity and bilateral trade flows. The estimation results of the TFP equation implied by this model are robust with respect to the choice of the interaction matrix. However using the $J$ test to select an interaction matrix leads to a model selection problem. To overcome this problem, we use the $M J$ test which indicates that the interaction matrix based on a function of the capacity of absorption of new technologies and trade flows is the most appropriate amongst the three interaction matrices we consider.

The obtained estimation results are consistent with those of Ertur \& Koch (2011) and Coe et al. (1997) and highlight the heterogeneity of the international diffusion of knowledge. As al-

ready noted by Ertur \& Koch (2011), this empirical evidence cannot be captured by the standard Howitt \& Aghion (1998) and Howitt (2000) models, which assume that USA are the unique global technological leader, whereas the integrated multi-country Schumpeterian growth model allows the emergence of local technological leaders. Using the selected trade flows based interaction matrix, we show that indeed USA, but also Germany and Japan actually play the role of local local technological leaders.

We believe that the suggested interaction matrix selection procedure will be helpful for applied researchers. 


\section{Acknowledgements}

We would like to thank Matthias Pécot and Yvan Stroppa for valuable research assistance. Also, we benefit from the support of the Centre de Calcul Scientifique en région Centre to perform all Monte Carlo simulations. The authors also acknowledge the financial support of the Region Centre Val de Loire (APR-IA 2014 00094514). We are also grateful to Ingmar Prucha, Lung-Fei Lee, Fei Jin and the participants of the $14^{\text {th }}$ international workshop on Spatial econometrics and statistics in Paris, $7^{\text {th }}$ Jean Paelinck Seminar in Saragossa, $26^{\text {th }} \mathrm{EC}^{2}$ conference hosted in Edinburgh, the $5^{\text {th }}$ Shanghai Econometrics Workshop and the Asian Meeting of the Econometric Society, Kyoto, 2016. 


\section{References}

Akerlof, G. A. (1997), 'Social distance and social decisions', Econometrica 65, 1005-1027.

Anselin, L. (1988), 'Model validation in spatial econometrics: a review and evaluation of alternative approaches', International Regional Science Review 11, 279-316.

Anselin, L. \& Bera, A. (1998), Spatial dependence in linear regression models with an application to spatial econometrics, in A. Ullah \& D. Giles, eds, 'Handbook of Applied Economics Statistics', Marcel Dekker, New York, pp. 237-289.

Ashraf, Q. \& Galor, O. (2013), "The "out of Africa" hypothesis, human genetic diversity, and comparative economic development', American Economic Review 103(1), 1-46.

Atkinson, A. (1970), 'A method for discriminating between models.', Journal of the Royal Statistical Society, Serie B 32, 323-353.

Burridge, P. (2012), 'Improving the J test in the SARAR model by likelihood-based estimation', Spatial Economic Analysis 7, 75-107.

Burridge, P. \& Fingleton, B. (2010), 'Bootstrap inference in spatial econometrics: the J-test', Spatial Economic Analysis 5, 93-119.

Caselli, F. (2005), Accounting for cross-country income differences, Vol. 1, Elsevier, chapter 9, pp. 679-741.

Cavalli-Sforza, L. L., Menozzi, P. \& Piazza, A. (1994), The History and Geography of Human Genes, Princeton University Press.

Coe, D. T. \& Helpman, E. (1995), 'International R \& D spillovers', European Economic Review 39, 859-887.

Coe, D. T., Helpman, E. \& Hoffmaister, A. (1997), 'North-south spillovers', The Economic Journal 107, $134-149$. 
Cohen, D. \& Soto, M. (2007), 'Growth and human capital: good data, good results', Journal of Economic Growth 12, 51-76.

Comin, D., Easterly, W. \& Gong, E. (2010), 'Was the wealth of nations determined in 1000 BC?', American Economic Journal: Macroeconomics 2(3), 65-97.

URL: http://dx.doi.org/10.1257/mac.2.3.65

Cox, D. (1961), 'Tests of separate families of hypotheses', Proceedings of the Fourth Berkeley Symposium on Mathematical Statistics and Probability, Volume 1: Contributions to the Theory of Statistics 1, 105-123.

Cox, D. R. (1962), 'Further results on tests of separate families of hypothesis.', Journal of the Royal Statistical Society, Serie B 24, 406-424.

Davidson, R. \& Flachaire, E. (2008), 'The wild bootstrap, tamed at last', Journal of Econometrics 146, 162-169.

Davidson, R. \& MacKinnon, J. (2002), 'Bootstrap J tests of nonnested linear regression models', Journal of Econometrics 109, 167-193.

Davidson, R. \& Mackinnon, J. D. (1985), 'Heteroskedasticity-robust tests in regression directions', Annales de L'insee 59-60, 183-218.

Davidson, R. \& MacKinnon, J. G. (1981), 'Several tests for model specification in the presence of alternative hypotheses', Econometrica 49, 781-793.

Debarsy, N. \& Ertur, C. (2010), 'Testing for spatial autocorrelation in a fixed effects panel data model', Regional Science and Urban Economics 40, 453-470.

Ertur, C. \& Koch, W. (2007), 'Growth, technological interdependence and spatial externalities: theory and evidence', Journal of Applied Econometrics 22, 1033-1062.

Ertur, C. \& Koch, W. (2011), 'A contribution to the theory and empirics of schumpeterian growth with worldwide interactions', Journal of Economic Growth 16, 215-255. 
Fruchterman \& Reingold (1991), 'Graph drawing by force-directed placement', Software Practice and Experience 21(11), 1129-1164.

Godfrey, L. G. (1983), 'Testing non-nested models after estimation by instrumental variables or least squares.', Econometrica 51, 355-366.

Grossman, G. M. \& Helpman, E. (1991), Innovation and growth in the global economy, MIT Press, Cambridge, MA.

Hagemann, A. (2012), 'A simple test for regression specification with non-nested alternatives', Journal of Econometrics 166, 247-254.

Hall, R. E. \& Jones, C. I. (1999), 'Why do some countries produce so much more output per worker than others?', The Quarterly Journal of Economics 114, 83-116.

Hansen, L. P. (1982), 'Large sample properties of generalized method of moments estimators', Econometrica 50, 1029-1054.

Heston, A., Summers, R. \& Aten, B. (2006), 'Penn world table version 6.2'.

Howitt, P. (2000), 'Endogeous growth and cross-country income differences', The American Economic Review 90, 829-846.

Howitt, P. \& Aghion, P. (1998), 'Capital accumulation and innovation as complementary factors in long-run growth', Journal of Economic Growth 3, 111-130.

Jin, F. \& Lee, L.-F. (2013), 'Cox-type tests for competing spatial autoregressive models with spatial autoregressive disturbances', Regional Science and Urban Economics 43, 590-616.

Jin, F. \& Lee, L.-f. (2015), 'On the bootstrap for moran's I test for spatial dependence', Journal of Econometrics 184, 295-314.

Kelejian, H. H. (2008), 'A spatial J-test for model specification against a single or a set of non-nested alternatives', Letters in Spatial and Resource Sciences 1, 3-11. 
Kelejian, H. H. \& Piras, G. (2011), 'An extension of kelejian's J-test for non-nested spatial models', Regional Science and Urban Economics 41, 281-292.

Kelejian, H. H. \& Prucha, I. R. (1998), 'A generalized spatial two stage least squares procedure for estimating a spatial autoregressive model with autoregressive disturbances', Journal of Real Estate Finance and Economics 17, 99-121.

Kelejian, H. H. \& Prucha, I. R. (1999), 'A generalized moments estimator for the autoregressive parameter in a spatial model', International Economic Review 40, 509-533.

Kelejian, H. H. \& Prucha, I. R. (2007), 'Relative efficiencies of various predictors in spatial econometric models containing spatial lags', Regional Science and Urban Economics 37, 363-374.

Kelejian, H. H. \& Prucha, I. R. (2010), 'Specification and estimation of spatial autoregressive models with autoregressive and heteroskedastic disturbances', Journal of Econometrics 157, 5367.

Kelejian, H. H., Prucha, I. R. \& Yuzefovich, Y. (2004), Instrumental variable estimation of a spatial autoregressive model with autoregressive disturbances: Large and small sample results, in J. LeSage \& K. R. Pace, eds, 'Spatial and Spatiotemporal Econometrics, Advance in Econometrics', Vol. 18, Emerald Group Publishing, pp. 163-198.

Lee, L.-F. (2001), Generalized method of moments estimation of spatial autoregressive processes, Technical report.

Lee, L.-F. (2003), 'Best spatial two-stage least squares estimators for a spatial autoregressive model with autoregressive disturbances', Econometric Reviews 22, 307-335.

Lee, L.-F. (2007), 'GMM and 2SLS estimation of mixed regressive, spatial autoregressive models', Journal of Econometrics 137, 489-514.

Lee, S.-Y. (2008), Three essays on spatial econometrics and empirical industrial organization, PhD thesis. 
Lin, X. \& Lee, L.-F. (2010), 'GMM estimation of spatial autoregressive models with unknown heteroskedasticity', Journal of Econometrics 157, 34-52.

Liu, R. (1988), 'Bootstrap procedures under some non-i.i.d, models', Annals of Statistics 16(4), 1696-1708.

Liu, X., Lee, L.-F. \& Bollinger, C. R. (2010), 'An efficient GMM estimator of spatial autoregressive models', Journal of Econometrics 159, 302-319.

Liu, X., Patacchini, E. \& Zenou, Y. (2014), 'Endogenous peer effects: local aggregate of global average?', Journal of Economic Behavior and Organization 103, 39-59.

MacKinnon, J. D., White, H. \& Davidson, R. (1983), 'Tests for model specification in the presence of alternative hypotheses', Journal of Econometrics 21, 53-70.

Mammen, E. (1992), When does bootstrap work? Asymptotic results and simulations, Springer, New York.

Mankiw, G. N., Romer, D. \& Weil, D. N. (1992), 'A contribution to the empirics of economic growth', Quarterly Journal of Economics 107, 407-437.

Melitz, J. \& Toubal, f. (2014), 'Native language, spoken language, translation and trade', Journal of International Economics 93, 351-363.

Nei, M. (1973), 'Analysis of gene diversity in subdivided populations', Proceedings of the National Academy of Sciences of the United States of America 70, 3321-3323.

Nelson, R. R. \& Phelps, E. S. (1966), 'Investment in humans, technological diffusion, and economic growth', The American Economic Review 56, 69-75.

Pesaran, H. M. (1974), 'On the general problem of model selection', The Review of Economic Studies 41, 153-171. 
Pesaran, H. M. \& Deaton, A. (1978), 'Testing non-nested nonlinear regression models', Econometrica 46, 677-694.

Pesaran, H. M. \& Weeks, M. (2001), Non-nested hypothesis testing: an overview, in B. H. Baltagi, ed., 'A Companion to Theoretical Econometrics', Blackwell Publishers Ltd.

Putterman, L. \& Weil, D. N. (2010), 'Post-1500 population flows and the long-run determinants of economic growth and inequality', The Quarterly Journal of Economics 125(4), 1627-1682. URL: http://dx.doi.org/10.1162/qjec.2010.125.4.1627

Reynolds, J., Weir, B. S. \& C.C., C. (1983), 'Estimation of the coancestry coefficient: Basis for a short-term genetic distance', Genetics 105(3), 776-779.

Spolaore, E. \& Wacziarg, R. (2009), 'The diffusion of development', The Quarterly Journal of Economics 124, 469-529.

Spolaore, E. \& Wacziarg, R. (2013), 'How deep are the roots of economic development?', Journal of Economic Literature 51, 325-369.

Wright, S. (1965), 'The interpretation of population structure by f-statistics with special regard to systems of mating', Ecovution . 
Table 7: Matrix of significant elasticities at 5\% for OECD countries using trade flows ( $W 3$ )

\begin{tabular}{|c|c|c|c|c|c|c|c|c|c|c|c|c|}
\hline & AUS & AUT & BEL & CAN & DNK & FIN & FRA & GER & GRC & IRL & ITA & JPN \\
\hline AUS & 0.1787 & 0.0003 & & - & 0.0003 & 0.0004 & 0.0017 & 0.0039 & 0.0001 & 0.0005 & 0.0018 & 0.0090 \\
\hline AUT & - & 0.1788 & 0.0014 & - & 0.0004 & 0.0004 & 0025 & 0165 & 0001 & - & 0.0036 & 0.0017 \\
\hline BEL & - & - & 0.1790 & - & 0.0003 & 0.0003 & 0057 & 0081 & 0.0001 & 0.0007 & 0.0021 & 0.0015 \\
\hline CAN & 0.0003 & - & 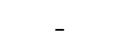 & 1796 & - & - & .0012 & - & - & - & 0.0010 & 0.0042 \\
\hline DNK & - & 0.0006 & 0.0018 & - & 0.1787 & 0.0013 & 0.0029 & 0.0095 & 0.0001 & 0.0005 & 0.0022 & 0.0017 \\
\hline FIN & 0.0002 & 0.0006 & 0.0015 & - & 0.0013 & 0.1787 & 0.0024 & 0.0076 & 0.0001 & 0.0005 & 0.0021 & 0.0030 \\
\hline FRA & - & 0.0005 & 0.0033 & - & 0004 & 0.0004 & 0.1792 & 0.0079 & 0.0001 & 0.0006 & 0.0041 & 0.0019 \\
\hline GER & - & 0.0021 & 0033 & 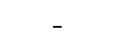 & 0009 & 0.0006 & 0.0054 & 0.1801 & 0.0002 & 0.0008 & 0.0044 & 0.0032 \\
\hline GRC & - & 0.0005 & 0015 & - & 0005 & 0.0004 & 0.0033 & 0.0063 & 0.1786 & 0.0004 & 0.0056 & 0.0019 \\
\hline IRL & - & 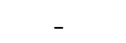 & $0.000 s$ & - & 0004 & 0.0003 & 0.0020 & 0.0032 & - & 0.1787 & 0.0012 & 0.0025 \\
\hline ITA & 0001 & 0.0010 & 0.0020 & - & 4 & 0.0003 & 49 & 79 & 0002 & 0.0004 & 0.1790 & - \\
\hline JPN & 011 & 0.0003 & - & 001 & 0004 & 0.0002 & 015 & 0.0033 & - & 0.0005 & .0014 & 0.1798 \\
\hline NLD & - & 0.0005 & 0045 & 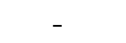 & 0005 & 0.0005 & .0032 & 0.0092 & 0.0001 & 0.0007 & .0019 & .0024 \\
\hline NZL & .0083 & - & - & - & 0003 & 0.0003 & 0.0013 & 0.0027 & 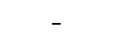 & 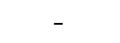 & 0.0013 & 0.0072 \\
\hline NOR & - & 0.0005 & 0.0013 & 0011 & 0.0029 & 0.0016 & 0.0022 & 0.0064 & 0.0001 & 0.0006 & 0.0019 & 0.0027 \\
\hline PRT & - & 0.0003 & 0.0011 & - & 0.0002 & 0.0002 & 0.0032 & 0.0044 & 0.0000 & 0.0002 & 0.0025 & 0.0010 \\
\hline ESP & - & 0.0005 & 0015 & - & 0003 & 0.0003 & & 0.0060 & & & .0035 & 0.0015 \\
\hline SWE & - & 0006 & 01 & - & & 0.0025 & & & & & & .0021 \\
\hline CHE & 0002 & 0019 & 0 & - & & & & & & & & 0021 \\
\hline GBR & & 0.0004 & 002 & 000 & & & & & & & & .0030 \\
\hline USA & 03 & - & - & 06 & 2 & 0.0 & 16 & 34 & 0.0000 & 0.0005 & & 0.0089 \\
\hline ARG & $\overline{001}$ & - & $\overline{000}$ & - & $\overline{0002}$ & 0.0002 & 0020 & 0.0025 & & & 21 & 0.0019 \\
\hline BOL & - & - & - & - & 01 & & & & & - & 0.0007 & 0.0023 \\
\hline BRA & - & 0.0002 & 0.0005 & $000 s$ & 0001 & 0.0002 & 0.0012 & 0.0031 & & - & 0.0017 & 0.0021 \\
\hline BFA & 0000 & 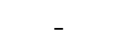 & 000 & 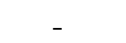 & 02 & - & 42 & & & 0.0001 & 0.0005 & 0.0010 \\
\hline CHL & 002 & - & 000 & - & 0002 & 000 & 16 & 0.0025 & & 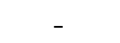 & & 0.0029 \\
\hline CHN & 0002 & 0.0002 & - & - & - & 0.0003 & & 24 & - & - & & 0.0080 \\
\hline COL & - & - & - & - & - & 0.0001 & & 17 & - & - & & 0.0020 \\
\hline $\mathrm{Cl}$ & - & - & 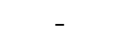 & - & - & - & & 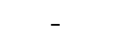 & - & - & & .0021 \\
\hline C & - & - & 000 & 001 & 000 & - & & - & - & - & & - \\
\hline CYP & - & 0003 & & - & 0004 & 0.0002 & 17 & .0040 & 0.0021 & .0003 & 28 & 0.0030 \\
\hline ECU & - & - & 500 & - & & - & 10 & 0.0018 & & - & 0.0012 & 0.0027 \\
\hline EGY & 0001 & 0003 & .000 & - & 0003 & 0.0003 & 22 & 0.0029 & 0.0001 & 0.0003 & 0.0025 & 0.0016 \\
\hline & 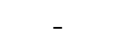 & 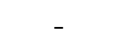 & 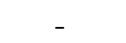 & - & 0001 & 0.0001 & 0.0008 & 0.0011 & & 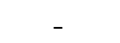 & 0.0005 & 0.0015 \\
\hline & - & - & 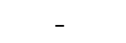 & - & 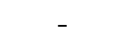 & - & 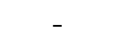 & - & 0001 & - & - & - \\
\hline $\mathrm{N}$ & 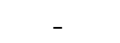 & 004 & - & 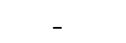 & Dog & $\mathrm{OOg}$ & & 01. & & 0003 & .0035 & 0.0018 \\
\hline & 0003 & - & 0 & - & 0002 & & & 0026 & 0000 & - & .0010 & 0.0024 \\
\hline & - & - & - & - & 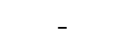 & 000 & & - & 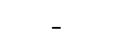 & 0.0002 & - & 0.0027 \\
\hline M & ل & - & 000 & - & 0001 & - & & OQ1 & & - & 0.0007 & 0.0013 \\
\hline M & 008 & - & - & - & 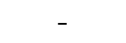 & 0001 & 99 & 17 & - & 0.0003 & 0.0006 & 0.0083 \\
\hline M & 0008 & - & - & - & 0002 & - & 0.0043 & 0.0019 & 0.0001 & 0.0002 & 0.0012 & 0.0021 \\
\hline & - & - & - & - & - & 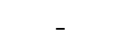 & 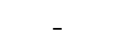 & - & - & - & - & - \\
\hline $\mathrm{NI}$ & - & - & 000 & - & 0002 & 0001 & - & - & - & - & - & 0.0020 \\
\hline PAN & - & - & - & - & 0002 & 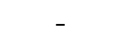 & & 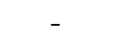 & .0001 & - & - & 0.0156 \\
\hline & - & - & 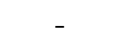 & - & 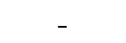 & 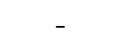 & & 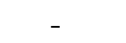 & - & 0001 & .0006 & 0.0020 \\
\hline & - & - & 000 & - & 000 & & & & & - & .0010 & 0.0026 \\
\hline & $000 ؟$ & 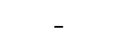 & 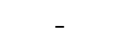 & - & 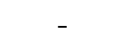 & 0.0002 & & & & .0003 & 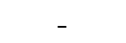 & 0.0090 \\
\hline ROM & - & 0.001 & 0.001 & - & 0003 & - & & 82 & 0.0007 & 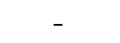 & 0.0065 & - \\
\hline & 00 & 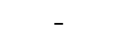 & - & - & - & 000 & & 116 & 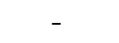 & - & 0.0007 & 0.0072 \\
\hline & 0005 & 000 & 00 & - & 002 & $\mathrm{Oeg}$ & & & - & 0.0003 & 0.0014 & 0.0026 \\
\hline SYR & - & 000 & 001 & - & 02 & 0.0002 & & & 0.0002 & - & 0.0029 & 0.0019 \\
\hline THA & 0005 & - & - & - & 0.0002 & 0.0002 & 0.0009 & 0.0018 & - & - & 0.0006 & 0.0090 \\
\hline TTO & 0.0002 & - & - & 0.0021 & - & - & - & 18 & - & 0.0004 & 0.0009 & 0.0026 \\
\hline TUN & - & 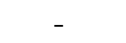 & & - & 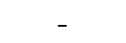 & 0.0001 & & & & - & 0035 & - \\
\hline TUR & .000 & 000 & 00 & - & 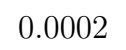 & 0.0003 & & & & & 028 & .0014 \\
\hline U & - & 0.0002 & 0.0006 & 000 & 003 & - & & 114 & 0.0000 & 0.0002 & 0.0009 & 0.0018 \\
\hline & - & - & - & - & 0.0001 & - & & 0.0016 & 0.0000 & - & 0.0017 & 0.0013 \\
\hline VEN & 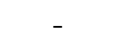 & 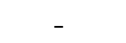 & 0.0004 & 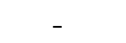 & - & 0.0001 & 0.0008 & 0.0016 & - & 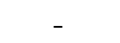 & 0.0013 & 0.0017 \\
\hline
\end{tabular}

- denotes non significant (at the 5\% threshold) while all figures are significant impact at the $5 \%$ level. 
Table 8: Matrix of significant elasticities for OECD countries using trade flows (W3), Cont'd

\begin{tabular}{|c|c|c|c|c|c|c|c|c|c|c|c|}
\hline & NLD & NZL & NOR & PRT & ESP & SWE & CHE & GBR & USA & BRA & $\mathrm{CHN}$ \\
\hline AUS & 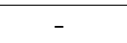 & 0.0016 & 0.0001 & - & 0.0004 & 0.0010 & 0.0007 & 0.0033 & 0.0090 & 0.0003 & 0.0027 \\
\hline AUT & 0.0016 & - & - & 0.0003 & 0.0007 & 0.0008 & 0.0016 & 0.0016 & 0.0023 & - & - \\
\hline BEL & 0.0059 & 0.0000 & - & 0.0003 & 0.0008 & 0.0011 & 0.0006 & 0.0029 & 0.0028 & 0.0003 & - \\
\hline CAN & - & 0.0001 & - & - & - & 0.0004 & - & 0.0014 & 0.0248 & 0.0003 & - \\
\hline DNK & 0.0030 & 0.0001 & 0.0013 & 0.0005 & 0.0007 & 0.0048 & 0.0008 & 0.0035 & 0.0024 & 0.0002 & 0.0010 \\
\hline FIN & 0.0018 & - & 0.0010 & 0.0004 & 0.0007 & 0.0048 & 0.0009 & 0.0032 & 0.0035 & 0.0002 & 0.0010 \\
\hline FRA & 0.0021 & - & 0.0002 & 0.0005 & 0.0023 & 0.0007 & 0.0010 & 0.0031 & 0.0036 & 0.0002 & 0.0009 \\
\hline GER & 0.0038 & - & 0.0003 & 0.0005 & 0.0014 & 0.0012 & 0.0020 & 0.0033 & 0.0040 & 0.0003 & 0.0014 \\
\hline GRC & 0.0024 & 0.0001 & 0.0002 & 0.0002 & 0.0012 & 0.0007 & 0.0007 & 0.0024 & - & 0.0002 & 0.0007 \\
\hline IRL & 0.0014 & - & 0.0002 & 0.0002 & 0.0006 & 0.0006 & 0.0004 & 0.0120 & 0.0057 & - & - \\
\hline ITA & 0.0023 & 0.0000 & 0.0001 & 0.0002 & 0.0015 & 0.0007 & 0.0014 & 0.0025 & 0.0022 & 0.0003 & 0.0008 \\
\hline JPN & - & 0.0003 & 0.0001 & - & - & 0.0006 & 0.0007 & 0.0016 & 0.0120 & 0.0005 & 0.0062 \\
\hline NLD & 0.1791 & - & 0.0003 & 0.0003 & 0.0009 & 0.0012 & 0.0007 & 0.0038 & 0.0038 & 0.0004 & 0.0009 \\
\hline NZL & - & 0.1786 & 0.0002 & - & - & 0.0008 & 0.0006 & 0.0027 & 0.0067 & - & 0.0019 \\
\hline NOR & 0.0021 & - & 0.1787 & 0.0004 & 0.0008 & 0.0063 & 0.0007 & 0.0040 & 0.0035 & - & 0.0010 \\
\hline PRT & 0.0015 & - & 0.0002 & 0.1786 & 0.0051 & 0.0004 & 0.0004 & 0.0019 & 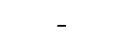 & 0.0003 & - \\
\hline ESP & 0.0015 & - & 0.0001 & 0.0009 & 0.1788 & 0.0006 & 0.0006 & 0.0027 & 0.0023 & 0.0002 & 0.0008 \\
\hline SWE & 0.0028 & - & 0.0020 & 0.0004 & 0.0007 & 0.1789 & 0.0009 & 0.0042 & 0.0035 & - & - \\
\hline CHE & 0.0024 & - & - & 0.0003 & 0.0008 & 0.0009 & 0.1788 & 0.0024 & 0.0032 & 0.0002 & - \\
\hline GBR & 0.0032 & 0.0001 & 0.0005 & 0.0005 & 0.0012 & 0.0013 & 0.0008 & 0.1792 & 0.0054 & 0.0003 & 0.0009 \\
\hline USA & - & 0.0001 & 0.0001 & 0.0001 & 0.0004 & 0.0006 & 0.0005 & 0.0020 & 0.1810 & 0.0007 & 0.0024 \\
\hline ARG & - & 0.0000 & - & - & 0.0014 & 0.0004 & 0.0005 & 0.0009 & 0.0070 & 0.0068 & 0.0011 \\
\hline BOL & - & 0.0000 & - & - & 0.0006 & 0.0006 & - & - & 0.0052 & 0.0057 & - \\
\hline BRA & 0.0006 & 0.0000 & - & 0.0001 & 0.0006 & 0.0005 & 0.0006 & 0.0009 & 0.0071 & 0.1787 & - \\
\hline BFA & 0.0005 & - & - & - & 0.0004 & - & - & 0.0005 & 0.0009 & - & 0.0004 \\
\hline CHL & - & 0.0001 & 0.0001 & 0.0001 & 0.0013 & 0.0007 & 0.0004 & 0.0009 & 0.0084 & 0.0030 & 0.0014 \\
\hline CHN & - & 0.0001 & 0.0001 & - & 0.0003 & 0.0005 & 0.0003 & 0.0007 & 0.0028 & 0.0003 & 0.1789 \\
\hline COL & - & - & - & - & 0.0007 & 0.0003 & 0.0004 & 0.0007 & 0.0084 & 0.0010 & - \\
\hline CRI & 0.0003 & - & - & - & 0.0005 & - & 0.0002 & 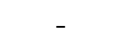 & 0.0118 & 0.0007 & - \\
\hline CUB & 0.0006 & 0.0002 & - & - & 0.0045 & - & 0.0002 & - & - & 0.0006 & 0.0045 \\
\hline CYP & 0.0008 & 0.0000 & 0.0005 & 0.0002 & 0.0010 & 0.0005 & 0.0004 & 0.0032 & 0.0033 & 0.0002 & - \\
\hline ECU & - & - & - & - & 0.0009 & - & 0.0004 & - & 0.0083 & 0.0013 & - \\
\hline EGY & 0.0007 & 0.0001 & - & - & 0.0006 & 0.0006 & 0.0006 & 0.0012 & 0.0028 & 0.0004 & 0.0005 \\
\hline SLV & - & 0.0001 & - & - & 0.0004 & 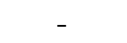 & 0.0002 & - & 0.0082 & 0.0003 & - \\
\hline HND & 0.0005 & 0.0000 & - & - & 0.0005 & - & 0.0003 & - & 0.0112 & 0.0004 & - \\
\hline HUN & 0.0014 & - & 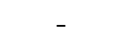 & - & 0.0007 & 0.0007 & 0.0010 & 0.0016 & - & 0.0003 & 0.0009 \\
\hline IND & 005 & 0.0001 & 0.0001 & - & 0.0002 & 0.0003 & 0.0007 & 0.0015 & 0.0029 & 0.0003 & 0.0007 \\
\hline JAM & 00 & 002 & - & - & 0.0002 & _- & - & 0.0015 & 0.0147 & 0.0006 & - \\
\hline MDG & 0.0004 & 0.0000 & - & - & 0.0003 & - & 0.0002 & 0.0007 & 0.0010 & 0.0002 & 0.0009 \\
\hline MYS & - & 0.0002 & - & - & - & 0.0003 & 0.0004 & 0.0012 & 0.0042 & 0.0002 & 0.0010 \\
\hline MUS & - & 0.0003 & - & .0001 & 0.0003 & - & 0.0005 & 0.0020 & - & 0.0002 & 0.0016 \\
\hline MEX & - & 0.0001 & 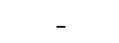 & - & 0.0004 & - & - & 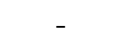 & 0.0186 & 0.0004 & - \\
\hline NIC & 0.0003 & 0.0001 & 0.0001 & - & 0.0006 & - & 0.0002 & 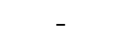 & 0.0069 & 0.0002 & - \\
\hline PAN & - & - & 0.0003 & - & 0.0004 & - & 0.0003 & - & 0.0045 & 0.0004 & - \\
\hline PRY & - & - & - & - & 0.0003 & - & 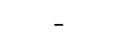 & 0.0008 & 0.0044 & 0.0076 & - \\
\hline PER & - & 0.000 & - & - & 0.0009 & 0.0004 & 0.0004 & - & 0.0080 & 0.0017 & 0.0010 \\
\hline PHL & 000 & 0.0002 & - & - & - & 0.0003 & 0.0003 & 0.0009 & 0.0054 & 0.0003 & 0.0013 \\
\hline ROM & 0.0014 & - & 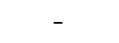 & - & 0.0005 & 0.0006 & 0.0009 & 0.0018 & 0.0018 & 0.0003 & 0.0006 \\
\hline SGP & 0.0004 & 0.0001 & 0.0001 & - & 0.0002 & 0.0003 & 0.0003 & 0.0011 & 0.0044 & 0.0001 & 0.0011 \\
\hline $\mathrm{ZAF}$ & 0009 & 0.0001 & - & 0.0001 & 0.0004 & 0.0004 & 0.0007 & 0.0030 & 0.0034 & 0.0003 & 0.0009 \\
\hline SYR & 0008 & 0.0000 & - & - & 0.0006 & 0.0004 & 0.0003 & 0.0011 & 0.0014 & 0.0003 & 0.0008 \\
\hline THA & 0.0004 & 0.0001 & 0.0001 & - & - & 0.0003 & 0.0004 & 0.0008 & 0.0040 & 0.0002 & 0.0014 \\
\hline TTO & 0.0006 & 0.0002 & 0.0001 & - & 0.0004 & - & - & 0.0027 & 0.0153 & 0.0007 & - \\
\hline TUN & 0.0006 & 0.0000 & 0.0000 & 0.0001 & 0.0008 & 0.0003 & 0.0003 & - & 0.0009 & 0.0001 & - \\
\hline TUR & 0.0010 & 0.0000 & 0.0001 & - & 0.0008 & 0.0006 & 0.0007 & 0.0017 & 0.0023 & 0.0002 & 0.0006 \\
\hline UGA & 0.0005 & - & 0.0001 & - & 0.0003 & 0.0002 & 0.0003 & 0.0027 & 0.0012 & 0.0002 & 0.0006 \\
\hline URY & - & 0.0000 & - & - & 0.0011 & 0.0003 & 0.0004 & 0.0008 & 0.0038 & 0.0067 & 0.0007 \\
\hline VEN & 0.0004 & 0.0001 & - & 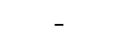 & 0.0006 & - & 0.0003 & 0.0007 & 0.0098 & 0.0010 & - \\
\hline
\end{tabular}

- denotes non significant (at the 5\% threshold) while all figures are significant impacts at the $5 \%$ level. 